\title{
Roles of Microvesicles in Tumor Progression and Clinical Applications
}

\author{
Shuangli Zhu' \\ Shiyu $\mathrm{Li}^{\prime}$ \\ Ming $\mathrm{Yi}^{1}$ \\ Ning Li $\mathbb{1 D}^{2}$ \\ Kongming $\mathrm{Wu}^{1,2}$ \\ 'Department of Oncology, Tongji \\ Hospital of Tongji Medical College, \\ Huazhong University of Science and \\ Technology, Wuhan, 430030, People's \\ Republic of China; ${ }^{2}$ Department of \\ Medical Oncology, The Affiliated Cancer \\ Hospital of Zhengzhou University \& \\ Henan Cancer Hospital, Zhengzhou, \\ 450008, People's Republic of China
}

Correspondence: Ning Li

Department of Medical Oncology, The Affiliated Cancer Hospital of Zhengzhou University \& Henan Cancer Hospital, Zhengzhou, 450008, People's Republic of China

Tel +86-37I-65587805

Email lining97@I26.com

Kongming $\mathrm{Wu}$

Department of Oncology, Tongji Hospital of Tongji Medical College, Huazhong University of Science and Technology, Wuhan, 430030, People's Republic of China

Tel +86-27-693784I 4

Email wukm_lab@163.com

\begin{abstract}
Microvesicles are extracellular vesicles with diameter ranging from 100 to 1000 $\mathrm{nm}$ that are secreted by tumor cells or other cells in the tumor microenvironment. A growing number of studies demonstrate that tumor-derived microvesicles are involved in tumor initiation and progression, as well as drug resistance. In addition, tumor-derived microvesicles carry a variety of immunogenic molecules and inhibit tumor response to immunotherapy; therefore, they can be exploited for use in tumor vaccines. Moreover, because of their high stability, tumor-derived microvesicles extracted from body fluids can be used as biomarkers for cancer diagnosis or assessment of prognosis. Tumor-derived microvesicles can also be deployed to reverse drug resistance of tumor regenerative cells, or to deliver chemotherapeutic drugs and oncolytic adenovirus for the treatment of cancer patients. This review summarizes the general characteristics of tumor-derived microvesicles, focusing on their biological characteristics, their involvement in tumor progression, and their clinical applications.
\end{abstract}

Keywords: tumor-derived microvesicles, metastasis, drug resistance, cancer vaccine, cancer

\section{Introduction}

Extracellular vesicles (EVs) are a heterogeneous collection of cell-derived membranous structures ${ }^{1}$ that can be divided into four types: microvesicles (MVs), exosomes, oncosomes, and apoptotic bodies. ${ }^{2,3}$ MVs are produced via shedding from the plasma membrane and have diameters ranging from 100 to $1000 \mathrm{~nm}^{1,4}$ MVs are also known as ectosomes, microparticles, or shedding vesicles. ${ }^{5,6}$ The proteins carried by MVs include CD40, $\beta 1$ integrins, matrix metalloproteinases (MMPs), ADP-ribosylation factor 6 (ARF6), and Rho family members. ${ }^{7,8}$ MVs are secreted into body fluids and have key roles in disease development and progression via regulation of intercellular signaling and intracellular communication. ${ }^{9}$

Tumor-derived MVs (TMVs) are MVs released by tumor cells in the tumor microenvironment (TME).$^{10,11}$ Components of the TME are closely related to tumor homeostasis, for example, tumor cells, immune and inflammatory cells, cancer-associated fibroblasts (CAFs), and extracellular matrix (ECM) components. ${ }^{12,13}$ TMVs can be absorbed by cells in the TME, such as CAFs, and have an influence on target cell behavior. They can also interact with the ECM by promoting its degradation, thereby facilitating cancer cell migration and invasion. Once shed, TMVs modulate tumor characteristics and activities including tumor invasion, metastasis, angiogenesis, drug resistance, and immunomodulation. ${ }^{14}$ Furthermore, TMVs can transfer bioactive contents including soluble factors, oncoproteins, chemokine receptors, oncogenes, transcripts of proteins, and microRNAs (miRNAs); thus, they are closely related to tumor 
development and progression. ${ }^{15}$ Moreover, TMVs are used in tumor vaccines to carry various immunogenic molecules to targeted tumor cells. ${ }^{16}$ Accumulating evidence indicates that TMVs could be used to deliver cancer therapeutics, including chemotherapeutic drugs and oncolytic adenoviruses. Overall, these results suggest that TMVs could represent novel mediators of oncogenesis, as well as having potential clinical applications. $^{17}$

\section{The Biogenesis and Characterization of MVs The Biogenesis of MVs}

MVs were first discovered in the 1970s in cell lines derived from a male patient with Hodgkin's disease. ${ }^{18}$ Subsequently, in the $1980 \mathrm{~s}$, Poste et $\mathrm{al}^{19}$ found that MVs spontaneously secreted by highly metastatic B16 mouse melanoma (F10). Once the MVs had fused with weakly metastatic B16 mouse melanoma cells (F1), they could increase the proficiency of F1 cells to metastasize to the lung. This pioneering research on MVs laid a solid foundation for numerous future studies, which have demonstrated the crucial parts played by MVs (through their molecular cargos) in immunomodulation and tumor progression. ${ }^{14}$ It is now well accepted that MVs originate from outward budding and fission of the cell membrane and are widely distributed in multiple body fluids, including urine, peripheral blood, and peritoneal effusions (Figure 1). The functions and components of MVs are associated with their cells of origin, which include tumor cells, stem cells, immune cells, and endothelial progenitor cells. $^{20}$ Interestingly, the abscission process is related to molecular rearrangements of the plasma membrane, which are affected by protein and lipid composition as well as $\mathrm{Ca}^{2+}$ levels. $^{7}$

An increase in intracellular $\mathrm{Ca}^{2+}$ leads to alterations of the asymmetric phospholipid distribution of the plasma membrane. Phosphatidylserine and phosphatidylethanolamine are located on the inner side of the cytomembrane. ${ }^{21}$ The asymmetry is maintained by $\mathrm{Ca}^{2+}$-dependent enzymes including aminophospholipid translocases, flippases and floppies, and calpain. ${ }^{22}$ Increased intracellular $\mathrm{Ca}^{2+}$ levels or release of $\mathrm{Ca}^{2+}$ by the endoplasmic reticulum can activate $\mathrm{Ca}^{2+}$-dependent enzymes, leading to the inhibition of translocases and activation of scramblase. As a result, phosphatidylserine and phosphatidylethanolamine are not returned to the inner side of the membrane, and the actin cytoskeleton remains depolymerized, promoting MV shedding. ${ }^{23,24}$

The degradation of MVs is controlled by small GTPases, including ADP-ribosylation factors (ARFs), ${ }^{25}$ Rab22a ${ }^{26}$ (also known as Rab22), ${ }^{27}$ and Rho. ${ }^{28}$ For example, ARF6 is a member of the ARF family of small GTPbinding proteins, ${ }^{10}$ and its activation is relevant to $\mathrm{MV}$ recycling and actin remodeling in the peripheral layer of cells. $^{29,30}$ Notably, activation of ARF-GTP also occurs in TMVs. In addition, myosin light-chain kinase (MLCK) can promote the production of MVs via MLCK-mediated myosin II light chain (MLC) phosphorylation. MLCK, a $\mathrm{Ca}^{2+} /$ calmodulin dependent kinase, can promote the

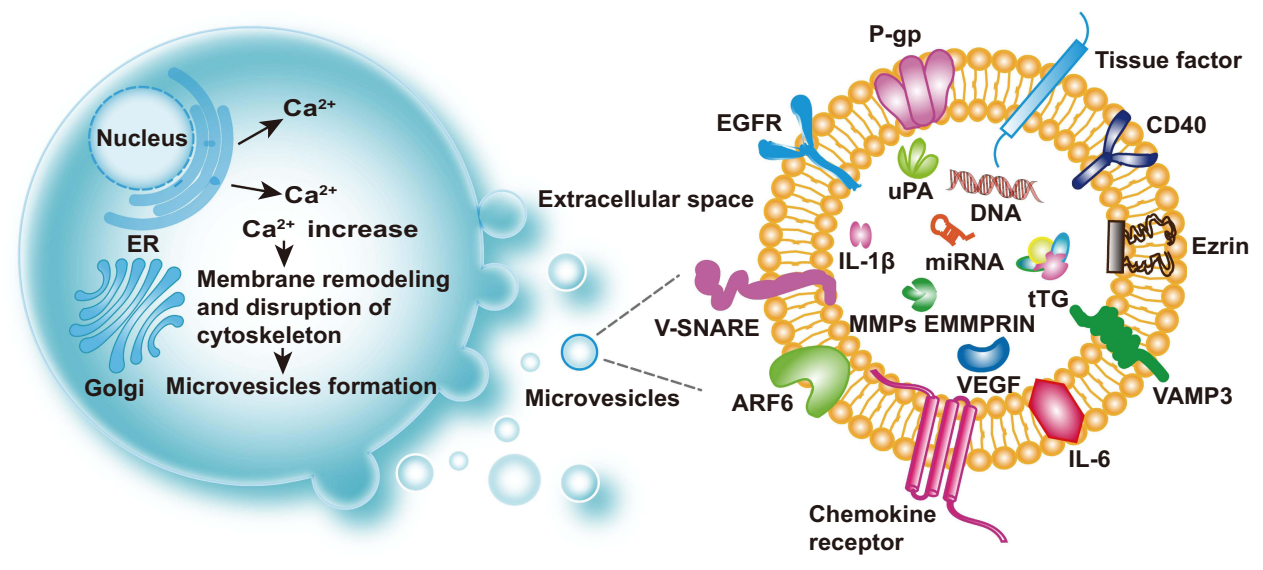

Figure I Biogenesis and cargos of MVs. Extracellular vesicles include microvesicles (MVs), exosomes, oncosomes, and apoptotic bodies. MVs are produced via shedding from the plasma membrane and have diameters ranging from 100 to $1000 \mathrm{~nm}$. Increased intracellular $\mathrm{Ca}^{2+}$ can activate $\mathrm{Ca}^{2+}$-dependent enzymes, leading to depolymerization of the actin cytoskeleton and membrane remodeling, then promotion of MV shedding. Representative cargos of MVs are shown: P-gP, TF, EGFR, v-SNARE, ARF6, chemokine receptor, IL-6, IL-I $\beta$, VAMP-3, Ezrin, CD40, uPA, DNA, microRNA, tTG, EMMPRIN, MMPs, and VEGF.

Abbreviations: TF, tissue factor; EGFR, epidermal growth factor receptor; v-SNARE, vesicular soluble N-ethylmaleimide-sensitive factor attachment protein receptor; ARF6, ADP-ribosylation factor 6; IL-6, interleukin 6; IL-I $\beta$, interleukin I $\beta$; VAMP-3, vesicle-associated membrane protein 3; CD40, cluster of differentiation 40; uPA, urokinase plasminogen activator; tTG, tissue-type transglutaminase; EMMPRIN, extracellular matrix metalloproteinase inducer; MMPs, matrix metalloproteinases; VEGF, vascular epithelial growth factor. 
contraction of the actin-based cytoskeleton via MLC phosphorylation. $^{31}$ The activation of ARF6 can promote the activation of MLCK via phospholipase D and extracellular signal-regulated kinase (ERK), contributing to the production of MVs. ${ }^{25,28,32}$ However, MV shedding is blocked by MLC phosphorylation, in a process mediated by protein kinase $\mathrm{C}$ and ARF-6-GDP. ${ }^{25}$ Rab22a has also been implicated in the formation of $\mathrm{MVs}^{26}$ and is associated with ARF6-regulated MVs trafficking. ${ }^{33}$ For example, the activation of Rab22a increased the production of MVs in breast cancer. Interestingly, Rab22a knockdown decreased hypoxia-induced generation of MVs but had only a slight effect on MV biogenesis under non-hypoxic conditions. ${ }^{34}$

Rho-family GTPases are also important mediators of MV production. ${ }^{35}$ Activation of RhoA is particularly effective for promoting the formation of MVs. The activation of RhoA has been shown to upregulate the downstream gene $\mathrm{ARF}^{36}$ or ARF1. ${ }^{37}$ Thus, RhoA can indirectly accelerate the activation of MLCK, leading to the release of MVs into the extracellular space. ${ }^{36}$ RhoA can also activate Rho-associated coiled-coil-containing kinases and LIM kinase, which promotes actin-myosinbased contraction for MV formation. ${ }^{35,36}$ In general, inhibition of ARF6 or its targets reduces the release of MVs. ${ }^{25}$

\section{Characterization and Cargo of MVs}

MVs can carry various proteins, some of which are present on their surfaces. ${ }^{38}$ Therefore, MVs can be identified by certain markers: CD40, MMPs, ARF6, and extracellular matrix metalloproteinase inducer (EMMPRIN). ${ }^{7,8,39,40}$ The cargos of MVs include membrane protein enzymes, growth factor receptors, cytokines, chemokines, ${ }^{41}$ lipids, and nucleic acids, including miRNAs, genomic DNA, and oncogenic genes. ${ }^{11,42}$ (Table 1). Lo Cicero et al ${ }^{43}$ demonstrated that Hsc70 was specifically concentrated on MVs, and MVs even contained Hsc70 constitutive partners at low levels. Bioactive molecules such as proteins, RNAs, and miRNAs are involved in tumor invasion and metastasis, and can change the function and phenotype of the receptor cells. ${ }^{44}$ EMMPRIN (also termed CD147), a transmembrane glycoprotein present on the surface of tumor cells, ${ }^{40}$ stimulates surrounding fibroblasts or tumor cells to produce MMPs. ${ }^{45}$ These MMPs can decompose the basement membrane, and facilitate the proliferation, invasion, and metastasis of malignant tumor cells. ${ }^{46}$ Menck et $\mathrm{al}^{4}$ showed that EMMPRIN could be used as a marker of MVs. EMMPRIN in a highly glycosylated form could activate the P38/mitogen-activated protein kinase (MAPK) signaling pathway of tumor cells and directly facilitate their invasion and metastasis.

\section{Methods for MVs Isolation and Detection Isolation of MVs}

Two methods have been developed for the isolation of MVs: traditional centrifugation and magnetophoretic sorting or immunoaffinity chromatography. The former approach is based on the physical properties of MVs and relies mainly on centrifugation and flotation in sucrose gradients, occasionally combined with size-exclusion chromatography. ${ }^{11}$ It is well accepted that the centrifugation should be performed at 10,000-20,000 $\mathrm{g}$ for 30-60 min. ${ }^{47}$ As the size distribution of MVs overlaps with that of other extracellular vesicles, isolation by centrifugation may lead to low purity of MVs. Cell sedimentation also depends on the density and cargo of vesicles. ${ }^{47,48}$ Therefore, some researchers have proposed combining differential centrifugation with sucrose gradient ultracentrifugation to remove exosomes, or carrying out immune separation. The latter approach is based on MVs' biochemical features and uses magnetophoretic sorting or immunoaffinity chromatography to isolate MVs. ${ }^{11}$

\section{Detection of MVs}

Once MVs have been isolated, they require further characterization. ELISA and fluorescent-activated cell sorting are frequently used methods for quantifying MVs. ${ }^{21,49}$ ELISA can capture a specific protein and produce a color change that is related to the concentration of the target protein. Annexin $\mathrm{V}$ is a commonly used marker for MV quantification by ELISA. ${ }^{21}$ Fluorescent-activated cell sorting can be used to detect MVs via conjugation with specific fluorescent antibodies. $^{49,50}$ In addition, electron microscopy provides direct evidence for the presence of MV structures and is more popular in the detection of MVs. ${ }^{48}$

\section{Tumor-Derived Microvesicles}

TMVs can be separated from a patient's biological fluids, such as peripheral blood, urine, saliva, and ascitic fluid. ${ }^{51}$ TMVs contain many surface determinants, including CD44H, major histocompatibility complex I (MHC I), EMMPRIN, chemokine receptors (CCR6, CX3CR1), and epithelial cell adhesion molecules. TMVs also contain growth factors including vascular endothelial growth factor (VEGF) and hepatocyte growth factor. ${ }^{52}$ These substances can promote tumor cell proliferation and adhesion 
Table I Biomarkers of MVs

\begin{tabular}{|c|c|c|c|c|c|}
\hline $\begin{array}{l}\text { Biomarker } \\
\text { Class }\end{array}$ & Name & MV Origin & Function & Target of Cargo & Ref. \\
\hline \multirow{15}{*}{$\begin{array}{l}\text { Membrane- } \\
\text { associated } \\
\text { molecules }\end{array}$} & ARF6 & Tumors & Remodeling of actin, regulation of $M V$ shedding & $\begin{array}{l}\text { VAMP3, MHC I, } \beta \\
\text { I-integrin }\end{array}$ & {$[25,28,29]$} \\
\hline & $\beta$ I-integrin & Tumors & Cell adhesion & NA & {$[166]$} \\
\hline & CD4I & $\begin{array}{l}\text { Plasma of CRC } \\
\text { patients }\end{array}$ & Platelet aggregation and adhesion & NA & {$[167]$} \\
\hline & $\begin{array}{l}\text { Tissue } \\
\text { factor (TF) }\end{array}$ & Activated platelets & Thrombus formation, activation of cancer stem cells, angiogenesis & NA & {$[168,169]$} \\
\hline & $\begin{array}{l}\text { EGFR } \\
\text { EGFRvIII }\end{array}$ & $\begin{array}{l}\text { Tumors } \\
\text { Tumors (glioma) }\end{array}$ & $\begin{array}{l}\text { Signal transduction, oncogenic growth factor receptor, activation } \\
\text { of transforming signaling pathways (AKT and ERK) }\end{array}$ & $\begin{array}{l}\text { NA } \\
\text { NA }\end{array}$ & $\begin{array}{l}{[60]} \\
{[57]}\end{array}$ \\
\hline & VAMP3 & Tumors & Promotion of matrix invasion by tumor cells & MTI-MMP & {$[28,170]$} \\
\hline & V-SNARE & Tumors & $\begin{array}{l}\text { Interaction with Rab22a, mediation of additional cargo trafficking } \\
\text { that converges on vesicle blebbing and shedding }\end{array}$ & Rab22a & {$[28]$} \\
\hline & P-gP & Tumors (ALL) & Promotion of chemotherapeutic resistance & NA & {$[102]$} \\
\hline & Ezrin & $\begin{array}{l}\text { Tumors (leukemic } \\
\text { and } \mathrm{BC} \text { ) }\end{array}$ & $\begin{array}{l}\text { Co-localizes with P-gp and assists interaction of plasma membrane } \\
\text { with cytoskeleton }\end{array}$ & NA & {$[96,171]$} \\
\hline & PS & All cells & Membrane phospholipids & NA & {$[172]$} \\
\hline & SM & All cells & Membrane phospholipids & NA & [53] \\
\hline & $\begin{array}{l}\text { CCL5, } \\
\text { CCR6 }\end{array}$ & Tumors (BC) & Metastasis, proliferation & NA & [173] \\
\hline & CCR6 & Tumors (GC) & $\begin{array}{l}\text { Cancer cell-induced angiogenesis, promotion of cancer cell } \\
\text { growth }\end{array}$ & NA & {$[173,174]$} \\
\hline & $\begin{array}{l}\text { CCR6, } \\
\text { CX3CRI, } \\
\text { CCL2 }\end{array}$ & Tumors (CRC) & AKT kinase activation, antiapoptotic effects on monocytes & NA & {$[52]$} \\
\hline & $\mathrm{CCL} 2$ & Tumors (OC) & Improving survival rate & Doxorubicin & {$[175]$} \\
\hline \multirow{8}{*}{$\begin{array}{l}\text { Intracellular } \\
\text { components }\end{array}$} & MMP2 & Tumors (BC, OC) & Degradation of extracellular matrix & NA & {$[176]$} \\
\hline & MMP9 & Tumors (BC, OC) & Degradation of extracellular matrix & NA & {$[176]$} \\
\hline & uPA & $\begin{array}{l}\text { Tumors }(B C, O C \text {, } \\
\text { PC) }\end{array}$ & Degradation of extracellular matrix, promotion of tumor invasion & NA & {$[84,176]$} \\
\hline & $\begin{array}{l}\text { EMMPRIN } \\
(C D \mid 47)\end{array}$ & Tumors (OC) & $\begin{array}{l}\text { Production of extracellular matrix metalloproteinases, induction } \\
\text { of proangiogenic, proliferation, and invasion activities }\end{array}$ & NA & {$[45,177]$} \\
\hline & VEGF & Tumors (BC) & Proangiogenic factor & NA & {$[178]$} \\
\hline & IL-I $\beta$ & Glial cells & Inflammation cytokine & NA & {$[179]$} \\
\hline & TGF- $\beta$ & Tumors (AML) & Decreasing cytotoxicity of NK cells & NKG2D & {$[180]$} \\
\hline & tTG & $\begin{array}{l}\text { Tumors (BC, } \\
\text { glioblastoma) }\end{array}$ & $\begin{array}{l}\text { Cross-linking with } \mathrm{FN} \text {, induction of recipient fibroblast } \\
\text { transformation }\end{array}$ & $\mathrm{FN}$ & [94] \\
\hline
\end{tabular}

(Continued) 
Table I (Continued).

\begin{tabular}{|c|c|c|c|c|c|}
\hline $\begin{array}{l}\text { Biomarker } \\
\text { Class }\end{array}$ & Name & MV Origin & Function & Target of Cargo & Ref. \\
\hline \multirow[t]{19}{*}{ Nucleic acids } & miR-19b & Tumors (RC) & Promotion of invasion and metastasis & NA & [90] \\
\hline & $\operatorname{miR}-29 c$ & Tumors (RC) & Promotion of invasion and metastasis & NA & [90] \\
\hline & miR-15I & Tumors (RC) & Promotion of invasion and metastasis & NA & [90] \\
\hline & miR-145 & Tumors (CRC) & Drug resistance & NA & {$[106]$} \\
\hline & miR-34a & Tumors (CRC) & Drug resistance & NA & {$[106]$} \\
\hline & miR-1246 & Tumors (CRC) & Promotion of angiogenic activities & NA & {$[181]$} \\
\hline & miR-92a & Tumors (CRC) & Tumor angiogenesis, cell proliferation & Down-regulated DKK-3 & {$[181,182]$} \\
\hline & $\begin{array}{l}\text { Let-7 } \\
\text { miRNA } \\
\text { family }\end{array}$ & Tumors (GC) & Oncogenesis, metastasis & NA & [183] \\
\hline & $\operatorname{miR}-1289$ & Tumors (GBM) & Enhancement of MV enrichment & $\begin{array}{l}\text { Zipcode-like } 25 \text {-nt } \\
\text { sequence, GALR3, MK/ } \\
\text { MDK }\end{array}$ & [184] \\
\hline & miR-2I & $\begin{array}{l}\text { Tumors (lung and } \\
\text { pancreatic cancer) }\end{array}$ & Induction of myoblast apoptosis & TLR7 & [185] \\
\hline & miR-143BPs & $\begin{array}{l}\text { THPI monocytes/ } \\
\text { macrophages }\end{array}$ & RNA drug delivery system & NA & {$[186]$} \\
\hline & miR-150 & Tumors & Promotion of tumorigenesis & Upregulation of VEGF & [187] \\
\hline & miR-23a & Hypoxic tumors & Decrease of NK cells' anti-tumor response & CDI07a (LAMPI) & [188] \\
\hline & miR-1227 & Tumors (PC) & Promotion of migration & NA & [174] \\
\hline & cDNA & Tumors & $\begin{array}{l}\text { Leads to mutations, deletions, rearrangements, and changes in } \\
\text { gene expression }\end{array}$ & NA & {$[151]$} \\
\hline & gDNA & Tumors & Role in genetic communication between cells & NA & {$[151]$} \\
\hline & ssDNA & Tumors & Role in genetic communication between cells & NA & {$[|5|]$} \\
\hline & c-Myc & Tumors & Oncogene & NA & {$[151]$} \\
\hline & pDNA & Tumors & Transfer of reporter function to recipient cells & NA & [189] \\
\hline
\end{tabular}

Abbreviations: MVs, microvesicles; ARF6, ADP-ribosylation factors 6; MHC I, major histocompatibility complex class I; VAMP3, vesicle-associated membrane protein 3; CD4I, cluster of differentiation 4I; CRC, colorectal cancer; TF, tissue factor; EGFR, epithelium growth factor receptor; MTI-MMP, membrane-type I matrix metalloprotease; v-SNARE, vesicular soluble N-ethylmaleimide-sensitive factor attachment protein receptor; P-gp, P-glycoprotein; ALL, acute lymphoblastic leukemia; PS, phosphatidylserine; SM, Sphingomyelin; CCL5, CC chemokine ligand 5; CCR6, CC chemokine receptor 6; BC, breast cancer; GC, gastric cancer; CRAC, colorectal adenocarcinoma; CCL2, CC chemokine ligand 2; OC, ovarian cancer; MMP2, matrix metalloproteinases 2; MMP9, matrix metalloproteinases 9; uPA, urokinase plasminogen activator; PC, prostate cancer; EMMPRIN, extracellular matrix metalloproteinase inducer; VEGF, vascular epithelium growth factor; IL-I $\beta$, interleukin-I $\beta$; TGF- $\beta$, transforming growth factor- $\beta$; AML, acute myeloid leukemia; tTG, tissue-type transglutaminase; GBM, human primary glioblastoma multiforme; FN, fibronectin; DKK-3, dickkopf-3; GALR3, galanin receptor 3; MK/MDK, midkine; TLR7, toll-like 7 receptor; NK cells, natural killer cells; LAMPI, lysosomal-associated membrane protein I; gDNA, genomic DNA; pDNA, plasmid DNA; ssDNA, single-stranded DNA; NA, not acquired.

and decomposition of the ECM to facilitate tumor metastasis. Several in vivo and in vitro experiments have confirmed that the amount of MV secretion is linked to tumor aggressiveness. Kim et $\mathrm{al}^{53}$ demonstrated that sphingomyelin is the active component in MVs that induces endothelial cell migration, tube formation, and angiogenesis.

\section{TMVs and the TME}

The occurrence and development of cancer strongly depend on the surrounding microenvironment, which contains both cellular and non-cellular components. ${ }^{54} \mathrm{TMVs}$ have important roles in the TME because they can efficiently transfer bioactive contents. ${ }^{11,15}$ TMVs can also regulate the immune response in the TME and are 
important mediators of tumor progression. ${ }^{55,56}$ Muralidharan Chari et $\mathrm{al}^{44}$ showed that TMVs released from invasive prostate cancer PC3 cells promoted the phosphorylation of ERK and upregulated MMP9, thereby increasing the apoptosis resistance of fibroblasts. In turn, the activated fibroblast-derived MVs promoted the invasion and metastasis of PC3 cells. This feedback phenomenon indicated that prostate-cancer-derived MVs activated stromal cells in the TME.

It is widely accepted that epidermal growth factor receptor variant III (EGFRvIII) is a truncated and oncogenic form of the epidermal growth factor receptor. AlNedaw et $\mathrm{al}^{57}$ found that TMVs from aggressive glioma containing EGFRvIII merged with the plasma membrane of indolent glioma cells, resulting in induced activation of MAPK and Akt, increased expression of EGFRvIIIregulated genes (VEGF, $\mathrm{Bcl}-\mathrm{x}(\mathrm{L}), \mathrm{p} 27)$, morphological transformation, and an increase in anchorage-independent growth. Overall, the TMVs caused a transfer of oncogenic activity. ${ }^{57}$ Tumor growth requires a continuous blood supply to satisfy the demand for nutrition and metabolism through angiogenesis. ${ }^{58}$ TMVs also contain regulators of angiogenesis such as VEGF, bFGF, and EGFR. ${ }^{59-61} \mathrm{Al}-$ Nedaw et $\mathrm{al}^{60}$ reported that TMVs stimulated stromal fibroblasts to secrete angiogenic precursors and delivered the activated EGFR from A431, A549, and DLD-1 cells to surrounding fibroblasts. Notably, VEGF expression in endothelial cells and autocrine activation of VEGF receptor-2 were attributed to intercellular transfer of EGFR.

VEGF, which is released from tumor cells, is a potent factor that promotes tumor angiogenesis. ${ }^{62} \mathrm{MV}$-containing tissue factor (TF) has been reported to induce the secretion of VEGF and stimulate angiogenesis. ${ }^{63}$ Szubert et $\mathrm{al}^{61}$ showed that TMVs could carry EMMPRIN (CD147) and promote the secretion of VEGF, thereby inducing angiogenesis of ovarian cancer. ${ }^{61}$ By contrast, Zhang et $\mathrm{al}^{59}$ found that TMV-delivered miR-29a/c suppressed vascular cell growth via inhibition of VEGF expression in gastric cancer cells. Therefore, they speculated that miRNA-containing MVs could be developed to inhibit tumor growth by blocking angiogenesis, a novel anti-tumor strategy. TMVs have also been shown to support thrombosis. It is well known that cancer cells can express TF and deliver TF-positive TMVs to the circulation. Geddings et al ${ }^{64}$ observed that TFpositive TMVs induced platelet activation, contributing to thrombosis in cancer patients. TF-positive TMVs could also destroy the function and structure of normal tissues and organs.

\section{TMVs and Immunosuppression}

Tumor cells can induce immunosuppression via TMVs so that abnormally proliferating tumor cells are not recognized and attacked by the immune system. TMVs participate in immunosuppression in two ways. TMVs regulate the proliferation and differentiation of various types of immune cells by delivering specific ligands for binding to immune cells. Tumor-associated macrophages, which are among the important immune cells in the TME, can be divided into the M1 population (pro-inflammation) and M2 population (anti-inflammation). Thus, M2-polarized macrophages can inhibit the anti-tumor immune response mediated by $\mathrm{T}$ cells and promote metastasis. ${ }^{65,66} \mathrm{Ma}^{\mathrm{Ct}} \mathrm{al}^{67}$ demonstrated that the development of M2-type macrophages via TMVs was mediated by the cGAS/STING/ TBK1/STAT6 pathway, with subsequent antiinflammation and immunosuppressive effects. IL- $1 \beta$ is an important proinflammatory cytokine. ${ }^{68,69}$ In the TME, IL$1 \beta$ is involved in the malignant behavior of tumor cells. ${ }^{70}$ Chen et $\mathrm{al}^{71}$ found that lung cancer microparticles (L-MPs) could induce macrophages to release IL-1 $\beta$, which in turn promoted the development of the immunosuppressive TME. The underlying mechanism was related to the activation of Toll-like receptor 3 and the Nod-like receptor protein 3 inflammasome via L-MPs.

TMVs have been reported to have a positive effect on the immunogenicity of dendritic cells (DCs) via reprogramming their antigen-processing mechanism and intracellular signaling transduction pathway, thereby promoting the antitumor response. ${ }^{72}$ Valenti et $\mathrm{al}^{73}$ reported that TMVs promoted the generation of myeloid-derived suppressive cells (MDSCs) via impairing the differentiation of monocytes to DCs. MDSCs further exert inhibitory effects on T cell proliferation and function through the secretion of transforming growth factor-beta (TGF- $\beta)^{8,56}$ TMVs have immunoregulation ability and have effects on multiple aspects of regulatory $\mathrm{T}$ cells (Tregs), including induction, promotion of expansion, upregulation of the suppressor function, and reinforcement of resistance to apoptosis. It is also possible for TMVs to present TGF- $\beta$ to $\mathrm{CD} 4^{+}$Tregs to promote immunosuppression. $^{74}$ TMVs inhibited IL-2 to weaken the anti-tumor response of natural killer cells (NK cells) and $\mathrm{CD}^{+} \mathrm{T}$ cells. Conversely, TMVs enhanced the immunosuppressive ability of $\mathrm{CD} 4^{+} / \mathrm{CD} 25^{+} / \mathrm{Foxp}^{+}$Tregs via TGF- $\beta .^{74}$ In addition, Taylor et $\mathrm{al}^{75}$ showed that TMVs could promote $\mathrm{T}$ cell apoptosis through Fas ligand (FasL; CD95L). 
FasL is a transmembrane protein that is a member of the tumor necrosis factor (TNF) superfamily and regulates apoptosis in the immune system. ${ }^{76}$ It has been reported that activated $\mathrm{T}$ cells with co-expression of Fas and FasL leads to activation-induced cell death. ${ }^{77}$ TMVs promote apoptosis through binding of FasL to the corresponding receptors on $\mathrm{CD}^{+} \mathrm{T}$ cells. Kim et $\mathrm{al}^{78}$ proved that the level of FasL-related MVs was related to tumor burden and lymph node involvement. TMVs could help cancer cells' evasion of the immune response. Reports have shown that TMVs could induce apoptosis in activated $\mathrm{CD}^{+} \mathrm{T}$ cells by exposing FasL and TNF-related apoptosis-inducing ligands. ${ }^{79-81}$ Cancer-cell-derived MVs contain miRNAs that regulate various immune components, including cytotoxic T lymphocytes, NK cells, MDSCs and Tregs to shape immune microenvironment. ${ }^{82}$ For example, Cui et $\mathrm{al}^{83}$ reported that leukemia-derived MVs induced $T$ cell exhaustion through delivery of multiple exogenous miRNAs into $\mathrm{T}$ cells by interfering in the NF- $\mathrm{\kappa B}$ pathway.

\section{TMVs and Invasion}

Tumor invasion depends on the degradation of the ECM, which is mainly caused by proteases including MMP-2, MMP-9, and urokinase-type plasminogen activator (uPA). These proteases can degrade basement membrane collagen and various components of the ECM including fibrin. ${ }^{23,47}$ TMVs have been shown to contain these proteases. Angelucci et $\mathrm{al}^{84}$ reported MVs derived from aggressive prostatic carcinoma cells released uPA, which adheres to and degrades collagen IV, and reconstructed the basement membrane. Graves et $\mathrm{al}^{85}$ found that MVs from ovarian cancer and malignant ascites contained activated MMP-2, MMP-9, and uPA, which resulted in ECM degradation and tumor invasion. In contrast, inhibition of MMP-2 and MMP-9 reduced tumor invasion. ${ }^{86}$

\section{TMVs and Tumor Metastasis-Related Phenotypes}

Tumor metastasis is one of the leading causes of death and the predominant challenge in the treatment of cancer patients. ${ }^{87}$ Metastasis is a process of multiple cascades, starting with the loss of adhesion of cancer cells at the primary tumor site. These cells then invade the surrounding tissue and enter the blood circulation. After evading the cytotoxicity of the host immune system, the cells extravasate and colonize a distant site for secondary growth. TMVs have been shown to be involved in this process. $^{88}$ Al-Nedaw et $\mathrm{al}^{57}$ demonstrated that TMVs could promote the horizontal transmission of oncogenes and transformation phenotypes among subpopulations of tumor cells. In addition, an EGFRvIII kinase inhibitor significantly reduced the signal responses of receptor cells mediated by TMVs, indicating a correlation between EGFRvIII carried by TMVs and the cascade reaction of receptor cells.

Lung cancer and breast cancer cells can absorb platelet-derived MVs and obtain platelet-related adhesion molecules, which are beneficial to tumor cell adhesion and metastasis. ${ }^{89}$ Skog et $\mathrm{al}^{41}$ found that brain microvascular epithelial cells could absorb MVs containing mRNAs and miRNAs secreted by malignant glioma cells. It was speculated that tumor cells could change the phenotype of stromal cells via miRNAs; this change was conducive to the survival and expansion of tumors. Tumor cells interfere with the gene stability of surrounding or distant cells via TMVs and destroy the structure and function of normal tissues and organs.

Given their high expression of the c-Myc oncogenic gene, TMVs may be involved in reverse transcription. Abnormal initiation of retrotransposon and insertion of complementary DNA may mediate gene mutation, rearrangement, and deletion. ${ }^{90}$ Grange et $\mathrm{al}^{90}$ reported that lung metastasis of renal carcinoma was promoted by MVs from $\mathrm{CD}_{105^{+}}$cancer stem cells. The molecular characterization of $\mathrm{CD} 105^{+} \mathrm{MVs}$ was used to identify a group of angiogenic mRNAs and miRNAs, including miR-19b, miR-29c, and miR-151, which were related to tumor progression and metastasis. Finally, cancer stem cell-derived MVs were identified; these could trigger angiogenesis switching and coordinate metastasis during tumor progression.

Zhang et $\mathrm{al}^{91}$ demonstrated that circulating TMVs could easily enter the lung parenchyma, where they were absorbed by local macrophages and induced the production of CC chemokine ligand 2 (CCL2). CD11 $\mathrm{b}^{+} \mathrm{Ly}_{6 \mathrm{C}}$ macrophages were attacked by CCL2, matured into an F4/ $80^{+}$phenotype producing IL- 6 , and triggered fibrin deposition. Therefore, circulating TMVs favor cancer metastasis to the lung, because IL-6 and fibrin deposition can provide chemical and mechanical signals that promote the survival and growth of lung cancer regenerative cells. The lipid receptor CD36 is the major mediator of the engulfing of pancreatic tumor-derived MVs by myeloid immune cells. Pancreatic tumor-derived MVs also promoted metastasis, which was related to CD36-regulated immune cell 
invasion and extravasation of MVs. ${ }^{92}$ Moreover, stimulation with TNF-a markedly increased the ability of TMVs to induce immigration of tumor cells. ${ }^{93}$

It is well accepted that epithelial-mesenchymal transition (EMT) has a crucial role in tumor metastasis. Recent studies have shown that TMVs also regulate EMT. Antonyak et $\mathrm{al}^{94}$ found that MVs released by breast cancer or glioma cells could mediate the transfer of crosslinking fibronectin and tissue transglutaminase to recipient cells, activating mitotic signal activity and endowing normal fibroblasts and epithelial cells with characteristics of cancer cells, such as anchorage-independent growth and enhancing survival capability. In addition, Castellana et $\mathrm{a}^{95}$ found that TMVs could induce fibroblast activation via phosphorylation of ERK1/2 and upregulation of MMP-9. The activated fibroblasts also promoted the release of MVs and reprogrammed them into CAFs. CAF-derived MVs may participate in the process by which CAFs induce EMT or stemness in cancer cells by releasing certain soluble factors. ${ }^{7}$

\section{TMVs and Drug Resistance}

Drug resistance refers to the ability of cancer cells to survive the effects of anti-tumor drugs. Anti-tumor treatment often fails owing to multidrug resistance (MDR), which is mainly mediated by a plasma membrane multidrug efflux transporter, P-glycoprotein (P-gp). ${ }^{24}$ MDR enables tumor cells to evade the cytotoxic effects of chemotherapeutic drugs through the active efflux of intracellular drugs. ${ }^{96}$ Experimental and clinical patient studies have indicated that TMVs are associated with drug resistance in various types of cancer, including breast cancer, ovarian cancer, colorectal cancer, and acute lymphoblastic leukemia (ALL). ${ }^{97}$ In addition, TMVs can be used to monitor disease burden, progression, and MDR development in myeloma. $^{98}$ It has been reported that P-gpmediated MDR can be acquired via TMVs, in a novel "non-genetic" acquisition process involving intercellular transfer. This finding indicates that TMVs represent an important medium for the transmission of MDR and suggests a new type of strategy to prevent MDR. ${ }^{99}$

In breast cancer, a protein carried by TMVs has been reported to promote drug resistance. For example, the transient receptor potential channel 5 (TRPC5) has been shown to regulate P-gp expression. ${ }^{100}$ TMVs transferred TRPC5 to human mammary epithelial cells (HMECs) and induced P-gp expression by activating nuclear factor of activated T cells subtype $\mathrm{C} 3$. Consistent with these results, a TRPC5-blocking antibody, T5E3, downregulated MDR1 expression and reduce P-gp production in HMECs. ${ }^{101}$ Circulating TMVs containing TRPC5 may transfer drug resistance to non-drug-resistant cells. Namee et $\mathrm{al}^{97}$ found that over-expression of ubiquitin C-terminal hydrolase L1, a deubiquitinating enzyme, induced MDR in breast cancer via upregulation of P-gp through the MAPK/ERK pathway. Bebawy et $\mathrm{al}^{102}$ co-cultured MVs of drug-resistant tumor cells with drug-sensitive tumor cells; the results suggested that the TMVs could bind to the drug-sensitive tumor cells and express P-gp, driving resistance to anthracycline. TMVs released by vinblastine-resistant leukemic cells, which overexpressed the MDR1/P-gp gene, conferred resistance on the sensitive ALL cell line CCFRCEM by the transfer of P-gp protein.

Drug resistance has been shown to be related to a reduction in the accumulation of P-gp substrate rhodamine 123 or doxorubicin. ${ }^{102}$ Some evidence also suggests that TMVs carrying P-gp are involved in the spread of drug resistance in ovarian cancer. ${ }^{103}$ miRNAs mediate therapeutic resistance through inducing EMT and stemness. ${ }^{104}$ A study by Klumper ${ }^{105}$ suggested that miR$142-5 p$ expression in both peripheral blood and bone marrow samples could predict the response of treatment-naïve chronic myeloid leukemia to imatinib. Akao et al ${ }^{106}$ established 5-fluorouracil (5-FU)-resistant human colon cancer DLD-1 cells (DLD-1/5-FU cells) from 5-FU-sensitive DLD-1 cells. Their results showed that intracellular and extracellular miR-145 and miR-34a were closely related to 5-FU resistance, and that the resistance was partly due to increased secretion of miR-145 and miR-34a by TMVs, resulting in lower intracellular levels of the two miRNAs.

\section{MVs and Intercellular Communication}

MVs are important mediators of intercellular communication. They perform this function in the following ways: 1) they deliver proteins, bioactive molecules, and mRNAs to target cells; 2) they fuse with target cells to transfer surface receptors from them, and perform biofunctions via binding between receptors and ligands; and 3) they stimulate target cells via surface ligands, functioning as a signaling complex. ${ }^{107}$ For example, Melzani et $\mathrm{al}^{108}$ found that MVs shed from melanoma can express FasL on their surface, enabling them to induce apoptosis by binding to CD95 on T-lymphocytes. This may be a mechanism by which cancer cells escape from tumorinfiltrating lymphocytes. There is also evidence that TMVs increase the survival of tumor-infiltrating lymphocytes. TMVs undergo changes in their immunophenotype and 
biological activity through communication with these cells.

Baj-Krzyworzeka et $\mathrm{al}^{52}$ found that MVs derived from human cancer cell lines transferred many tumor determinants (such as CCR6/CD44v7/8) to monocytes; these could protect monocytes from apoptosis by activating AKT kinase-phosphatidylinositide 3'-OH kinase. This suggested that TMVs might function as mediators of communication between monocytes and tumor cells. Samii et $\mathrm{al}^{109}$ proposed that miRNA-containing MVs could directly affect the phenotypic and functional characteristics of target cells. For example, miR-21 was reported to be overexpressed on cells of hematological malignancies such as leukemia, lymphoma, and multiple myeloma. ${ }^{110-112}$ Transfer of miR-21 by leukemia MVs to hematopoietic stem and progenitor cells (HSPCs) led to their overexpression, which induced HSPCs proliferation. It was shown that miR-29a regulated early hematopoiesis by inducing self-renewal capacity of myeloid progenitors and promoting their conversion into leukemia stem cells. Upregulation of an oncogenic miRNA (miR-29a) in MVs resulted in the transformation of normal HSPCs into leukemia-like cells. ${ }^{109,113}$

An increasing number of miRNAs have been shown to mediate proliferation, EMT, and cancer stemness through diverse targets. ${ }^{104}$ For example, Le et al ${ }^{114}$ demonstrated that MVs derived from murine and human breast cancer cells could be used to deliver miR-200 to nonmetastatic cancer cells, promoting mesenchymal-to-epithelial transition. Tumors expressing miR-200 and MVs from murine cancer and human xenograft models facilitated metastasis of poorly metastatic cells at both nearby and distant sites, and endowed these cells with the ability to colonize distant tissues in a miR-200-dependent manner. Finally, the results clarified that metastatic ability could be transferred via the uptake of MVs.

\section{MVs and Other EVs}

\section{Differences Between MVs and Other EVs}

As mentioned above, EVs include MVs, exosomes, oncosomes, and apoptotic bodies. EVs are commonly identified by their cellular origin, size, density, markers, molecular cargos, and so on ${ }^{115}$ (Table 2).

Exosomes, which range from 40 to $160 \mathrm{~nm}$ in diameter, ${ }^{3}$ originate from invagination of the endosomal limiting membrane and form as intraluminal vesicles (ILVs), resulting in the generation of multivesicular bodies
(MVBs). When an MVB has been generated, it can fuse with the plasma membrane to release ILVs, which are referred to as exosomes. ${ }^{116}$ The classical mechanism of the biogenesis of exosomes relies on the endosomal sorting complex required for transport (ESCRT). The ESCRT is a protein complex that is essential for the scission of ILVs into the MVB lumen. ${ }^{1,117}$ It is well accepted that exosomes can be distinguished via their markers, for example, ALIX, CD9, CD63, CD81, and heat shock protein. $^{3}$ The cargos of exosomes include mRNAs and non-coding RNAs, and cytoplasmic and membrane proteins such as receptors and major histocompatibility complex molecules. ${ }^{7,118,119}$ The methods used to isolate exosomes include ultracentrifugation, density gradient centrifugation, immunoprecipitation, and size-exclusion chromatography. $^{120}$ Electron microscopy, fluorescentactivated cell sorting with CD68 capture, and Western blotting are used for the detection of exosomes. ${ }^{7}$ Exosomes are important carriers in signal transduction among different types of cells in the TME. Multiple studies have confirmed the role of exosomes in the development and progression of hepatocellular carcinoma (HCC). ${ }^{121}$

Oncosomes, like MVs, are derived from the plasma membrane, which is shed from aggressive cancer cells. There are two types of oncosomes, including oncosomes (100-4000 $\mathrm{nm}$ in diameter) and large oncosomes (LOs, 1$10 \mu \mathrm{m}$ in diameter). ${ }^{122}$ Minciacchi et $\mathrm{al}^{7}$ found that the formation of LOs relied on the activation of the AKT1 and EGFR pathways. The markers of oncosomes include caveolin-1, ${ }^{123}$ and their cargos of oncosomes include oncogenic proteins, mRNAs, and non-coding RNAs. ${ }^{124}$ There are currently no standardized methods for the isolation of oncosomes; however, they are commonly identified by electron microscopy and confocal or optical microscopy. $^{124}$

Apoptotic bodies are outward blebbings of the apoptotic cell membrane, with diameters of 50-2000 nm. ${ }^{122}$ Apoptotic bodies contain nuclear fractions and cell organs. They can be identified by hallmarks including annexin V, DNA, and histones. ${ }^{123}$ Similar to the case of oncosomes, there are no standardized methods for isolation of apoptotic bodies. ${ }^{7}$ They are usually observed by electron microscopy.

\section{Cross-Talk Between MVs and Other EVs} JAK-STAT signaling mediates many immune regulatory processes, including recognition of tumor cells and 
Table 2 Distinctions Among Microvesicles, Exosomes, Oncosomes, and Apoptotic Bodies (Classification of Extracellular Vesicles)

\begin{tabular}{|c|c|c|c|c|}
\hline $\begin{array}{l}\text { Vesicle } \\
\text { Type }\end{array}$ & Microvesicles & Exosomes & Oncosomes & Apoptotic Bodies \\
\hline Origin & Plasma membrane & Multivesicular bodies (MVBs) & Plasma membrane & Plasma membrane \\
\hline Biogenesis & $\begin{array}{l}\text { Shedding from the plasma } \\
\text { membrane }\end{array}$ & $\begin{array}{l}\text { Fusion of endosomes with the plasma membrane } \\
\text { (exocytosis of MVBs) }\end{array}$ & $\begin{array}{l}\text { Shedding from } \\
\text { aggressive cancer } \\
\text { cells }\end{array}$ & $\begin{array}{l}\text { Outward blebbing of } \\
\text { apoptotic cell } \\
\text { membrane }\end{array}$ \\
\hline Size $(\mathrm{nm})$ & $100-1000$ & $40-160$ & $\begin{array}{l}100-4000 \text { (large } \\
\text { oncosomes, } 1000- \\
10,000)\end{array}$ & $50-5000$ \\
\hline Markers & $\begin{array}{l}\text { CD40, ARF6, EMMPRIN, integrin, } \\
\text { selectin }\end{array}$ & $\begin{array}{l}\text { Tetraspanins, ALIX, CD9, CD63, CD8I, HSP, } \\
\text { ESCRT, TSGI0I, flotillin }\end{array}$ & $\begin{array}{l}\text { Cav-I, CKI8, } \\
\text { HSP70, HSP90 }\end{array}$ & $\begin{array}{l}\text { Large amounts of } \\
\text { phosphatidylserine, } \\
\text { annexin V, DNA, } \\
\text { histones }\end{array}$ \\
\hline Contents & $\begin{array}{l}\text { mRNA, non-coding RNAs, } \\
\text { cytoplasmic and membrane } \\
\text { proteins, including receptors }\end{array}$ & $\begin{array}{l}\text { mRNA, non-coding RNAs, cytoplasmic and } \\
\text { membrane proteins, including receptors and major } \\
\text { histocompatibility complex molecules }\end{array}$ & $\begin{array}{l}\text { Oncogenic } \\
\text { proteins, mRNAs, } \\
\text { and non-coding } \\
\text { RNAs }\end{array}$ & $\begin{array}{l}\text { Nuclear fractions, cell } \\
\text { organelles }\end{array}$ \\
\hline $\begin{array}{l}\text { Major } \\
\text { pathway }\end{array}$ & $\mathrm{Ca}^{2+}$-dependent & ESCRT- dependent & $\begin{array}{l}\text { AKTI and EGFR } \\
\text { pathways }\end{array}$ & $\begin{array}{l}\text { Apoptosis-related } \\
\text { pathway }\end{array}$ \\
\hline $\begin{array}{l}\text { Detection } \\
\text { methods }\end{array}$ & EM, FACS & EM, FACS with CD68 capture and Western blotting & $\begin{array}{l}\text { EM, confocal, or } \\
\text { optical microscopy }\end{array}$ & EM, FACS \\
\hline $\begin{array}{l}\text { Isolation } \\
\text { methods }\end{array}$ & $\begin{array}{l}\text { Centrifugation }(10,000-20,000 \mathrm{~g}) \\
\text { magnetophoretic sorting or } \\
\text { immunoaffinity chromatography }\end{array}$ & $\begin{array}{l}\text { Ultracentrifugation ( } \geq 100,000 \mathrm{~g} \text { ), } \\
\text { immunoprecipitation (ExoQuick), SEC }\end{array}$ & $\begin{array}{l}\text { No standard } \\
\text { method }\end{array}$ & No standard method \\
\hline References & {$[1,4,7,8,21,23,24,41,47-50]$} & {$[1,3,7,118,120,123]$} & {$[7,123,124,190]$} & {$[7,122,123]$} \\
\hline
\end{tabular}

Abbreviations: CD9, cluster of differentiation 9; CD63, cluster of differentiation 63; CD8I, cluster of differentiation 8I; EM, electron microscopy; EMMPRIN, extracellular matrix metalloproteinase inducer; ESCRT, endosomal sorting complex required for transport; FACS, fluorescence-activated cell sorting; HSP, heat shock protein; SEC, size exclusion chromatography; PS, phosphatidylserine.

immune escape. ${ }^{125}$ Interferon- $\gamma$ (IFN- $\gamma$ )-induced STAT1 activation is related to the anti-tumor immune response; STAT1 is generally regarded as a inhibitor of tumor activity. Conversely, STAT3 is mainly associated with cancer cell survival, immunosuppression, and inflammation in the TME. ${ }^{126}$ Bourdonnay et al $^{127}$ reported that alveolar macrophage-derived MVs could secrete SOCS3, whereas exosomes secreted SOCS1; these proteins were absorbed via alveolar epithelial cells (AECs) and inhibited STAT activation. Moreover, SOCS3-containing MVs absorbed via AECs could suppress IL-6, leading to STAT3 activation. However, SOCS1-containing exosomes taken up by AECs could inhibit IFN- $\gamma$-induced STAT1 activation.

EGFR signaling mediated by EVs influenced tumor progress and metastasis. TMVs transferred oncogenic EGFR to other cancer or epithelial cells, increasing the growth and survival of glioma cells, ${ }^{57}$ and led to angiogenesis in human squamous cell carcinoma. ${ }^{60}$ Moreover, gastric cancer-derived exosomes also contained the oncoprotein EGFR, which eventually localized to the plasma membranes of liver stromal cells. Exosomemediated EGFR activated liver hepatocyte growth factor, bound to c-Met on tumor cells, and promoted the seeding and proliferation of cancer cells in metastasis. ${ }^{128}$ Amphiregulin is an EGFR ligand that facilitates the invasive ability of cancer cells. Higginbotham et $\mathrm{al}^{129}$ illustrated this phenomenon in breast and colon cancerderived exosomes. Subsequently, they found that the exosomes expressed EGFR and amphiregulin in colon cancer. ${ }^{130}$ Tumor-derived EVs have procoagulant properties that might cause tumor-associated thrombosis, which is related to metastasis. Gomes et al ${ }^{131}$ found that EVs (including MVs and exosomes) released by MA-MB-231 cells were enriched in TF, which induced the generation of 


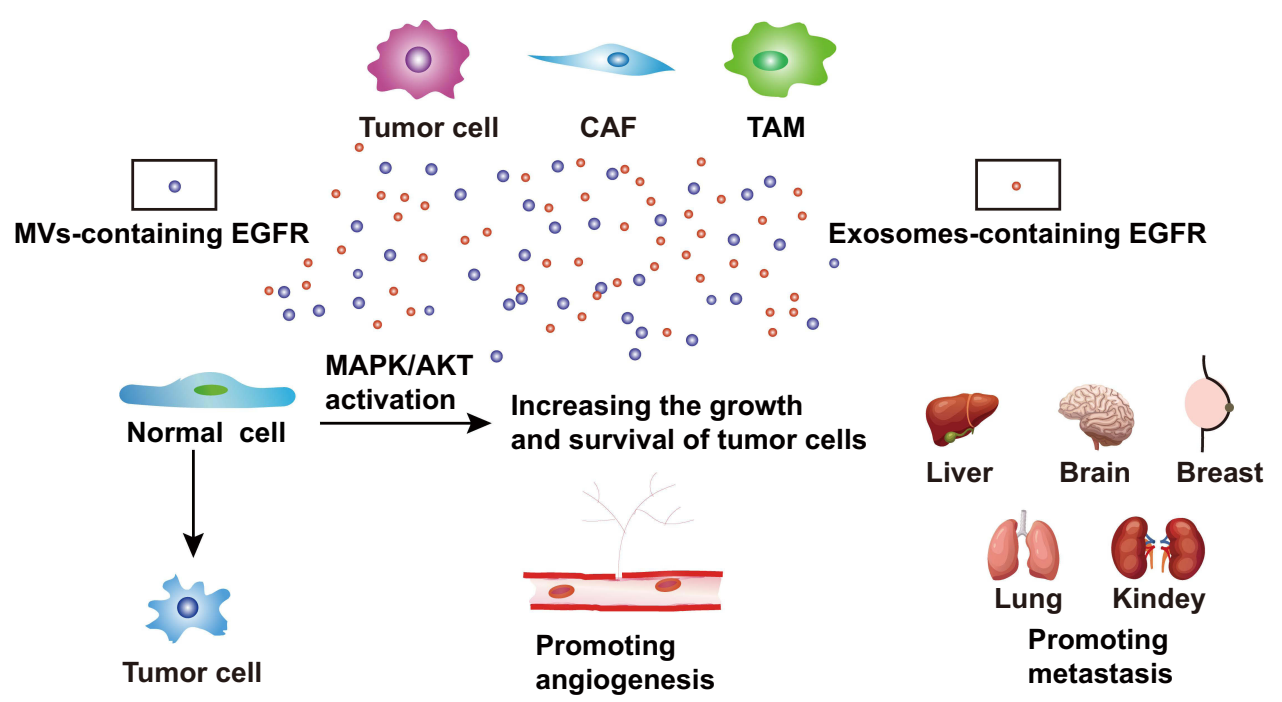

Figure 2 The cross-talk between MVs and exosomes. MVs and exosomes are released from many cells, including tumor cells, CAFs, and TAMs. They can secret MVscontaining EGFR and exosomes-containing EGFR, which influence tumor progression, for example, transforming normal cells into tumor cells, promoting angiogenesis and metastasis. Moreover, normal cells, which take up MVs and exosomes can increase the growth and survival of tumor cells by activating the MAPK/AKT pathway. Abbreviations: CAFs, cancer-associated fibroblasts; TAMs, tumor-associated macrophages; EGFR, epidermal growth factor receptor.

thrombin and subsequent plasma clotting and platelet aggregation (Figure 2).

\section{Clinical Applications of TMVs Cancer Vaccines}

The basic principle of tumor vaccines is to enhance the antitumor immunity of $\mathrm{T}$ cells using the characteristics of tumor antigens presented by MVs. TMVs are potential carriers for antigen delivery because they can carry many immunogenic molecules, for instance, proteins, nucleic acids, and polysaccharides. Moreover, TMVs can directly target cancer cells. ${ }^{16} \mathrm{EV}$ vaccines were first used to prevent infectious diseases, including diphtheria, Mycobacterium tuberculosis, and Bordetella pertussis. ${ }^{132-134}$ Subsequently, investigators found that EV vaccines could be adapted for tumor therapy. ${ }^{135}$ MVs released by macrophages infected with Listeria monocytogenes were shown to transfer Listeria monocytogenes antigens to DCs, thereby inducing protective $\mathrm{T}$ cell immunity. ${ }^{136}$ Dong et a ${ }^{137}$ suggested that an oral anti-tumor TMV-based vaccine could be absorbed by ileal epithelial cells (IECs). On the one hand, the TMVs could activate nucleotide-binding oligomerization domain 2 and downstream MAPK and NF-KB, causing IECs to release chemokines to recruit $\mathrm{CD} 103^{+} \mathrm{CD} 11 \mathrm{c}^{+}$DCs. On the other hand, they could be transported by IECs to the basolateral part, where DCs could capture the contents of TMVs crosspresenting antigen. Thus, TMVs could transfer antigens or innate signals (such as DNA) to intestinal mucosal DCs.
Tumor cells containing DNA and TMVs were exposed to ultraviolet light to induce release of antigen fragments. After being absorbed by DCs, the TMVs' DNA induced the expression of IFN-I by activating the cGAS/STING pathway. In turn, IFN-I enhanced the maturation of DCs by upregulating CD80, CD86, and MHCII. Then, the "armed" DCs activated tumor-specific T cells, resulting in the lysis of tumor cells. Zhang et al ${ }^{138-140}$ proposed TMVs as ideal candidates for use in developing novel and effective tumor vaccines. Pineda et $\mathrm{al}^{141}$ used non-irradiated and irradiated TMVs derived from C6 glioma cells to immunize rats with glioma. Compared with the control group (immunized with non-irradiated TMVs), the group treated with irradiated TMVs (IR-TMVs) showed increased release of TMVs with the specific antigen. The IR-TMVs were also conducive to the expansion of effector $T$ cells, enabling them to migrate into tumors and promote the death of tumor cells via immunogenicity. Therefore, the authors speculated that IRTMVs could be used as therapeutic anti-tumor vaccines.

Parenky et al ${ }^{142}$ prepared an oral tumor vaccine using TMVs extracted from mouse prostate cancer cells and evaluated its anti-tumor effects in vivo combined with cyclophosphamide and granulocyte-macrophage colonystimulating factor. The tumor vaccine based on the TMVs in combination with two drugs significantly reduced Tregs in vivo, indicating that the vaccine would have a strong anti-tumor effect. Pack et $\mathrm{al}^{143}$ combined TMVs derived from 4T1 tumor cells with 
immunostimulatory molecule B7-1 (CD80), anchored by glycosylphosphatidylinositol (GPI) and IL-12 molecules, to make a vaccine; then, tumor-bearing mice were treated with the TMV vaccine alone or in combination with an anti-cytotoxic T-lymphocyte-associated protein 4 monoclonal antibody. The combined therapy improved the survival rate of mice and reduced lung metastasis. In addition, it was verified that the vaccines exerted their effects through tumor-specific $\mathrm{CD} 8^{+} \mathrm{T}$ cell immunity.

TMV-mediated immunotherapy has been shown to be a potential enhancer of immunosuppressants for the treatment of metastatic triple-negative breast cancer. Bommireddy et $\mathrm{al}^{144}$ found the same effects of TMV vaccines in a mouse model of head and neck squamous cell carcinoma (HNSCC). They also found that the TMV vaccines could effectively inhibit tumor growth in MOC1 and MOC2 murine oral cancer models and cooperate with anti-PD1 to prolong the survival time of tumor-bearing mice. Moreover, TMV vaccines could be used to develop immunotherapies for HNSCC and to enhance the efficacy of immune checkpoint inhibitors.

\section{Biomarker}

Owing to their stability, TMVs extracted from body fluids of cancer patients can provide diagnostic information. ${ }^{41,145}$ Hou et $\mathrm{al}^{146}$ found that pyruvate kinase M2 (PKM2) could be isolated from the plasma of patients with HCC, suggesting that PKM2 in TMVs could be used as a potential diagnostic marker of HCC. Muralidharan-Char et $\mathrm{al}^{25}$ found that the activation of ARF was directly related to tumor progression and thus may represent a disease biomarker. A pilot study by Smalley et $\mathrm{al}^{147}$ identified eight tumor-related proteins in TMVs, comprising five proteins related to the EGFR pathway, the a-subunit of GsGTPbinding protein, resistin, and retinoic acid-induced protein 3. Thus, the protein composition of such TMVs could be used in the early detection of bladder cancer.

HER-2/neu is upregulated not only in breast cancer but also in other related carcinomas, for example, gastric cancer and ovarian cancer. ${ }^{148,149}$ Baran et $\mathrm{al}^{150}$ found higher expression levels of HER-2-/neu, MAGE-1, c-MET, and EMMPRIN in plasma samples of gastric cancer patients compared with control samples, suggesting that these proteins could be used as diagnostic markers. Zhong et $\mathrm{al}^{38}$ proposed EMMPRIN as a novel potential tumor marker that could be used to evaluate the prognosis of patients with malignant tumors at an early stage and to adjust the treatment plan, thereby improving the quality of life of cancer patients. Balaj et $\mathrm{al}^{151}$ observed amplification of the oncogene c-Myc in TMVs, suggesting that TMVs contain genetic information that could be a source of potential cancer biomarkers. Sun et a $1^{152}$ isolated and characterized TMVs from saliva of patients with lung cancer and found that they contained informative proteins, including BPI fold-containing family A member 1 (which is involved in the innate immune response), MUC5B (which is involved in the pathogenesis of pulmonary fibrosis), and Ras GTPase-activating-like protein (which is involved in tumor cell proliferation and transformation); these markers could be used to detect lung cancer in a non-invasive manner. Elevated levels of saliva MVs (SMVs) are associated with unfavorable clinicopathological features and decreased survival rate in patients with oral squamous cell carcinoma (OSCC). A study by Zhong et al ${ }^{153}$ suggested that SMVs from OSCC were potential biomarkers of malignant progression.

\section{Other Clinical Applications}

Stem-cell-like tumor repopulating cells (TRCs) play a vital part in reprogramming the tumor immunosuppressive microenvironment. ${ }^{154}$ Ma et $\mathrm{al}^{155}$ showed that TMVs loaded with anti-tumor drugs could reverse the drug resistance of TRCs or stem-cell-like cancer cells. In addition, TRCs had greater flexibility than differentiated cancer cells, and they preferentially absorbed TMVs with anticancer drugs, leading to the death of TRCs. Tang et $\mathrm{al}^{156}$ packaged chemotherapeutic drugs into TMVs, which could be collected and used to effectively kill tumor cells in mouse models without typical side effects. Studies have shown that TMVs are well-tolerated in clinical practice, and they achieved objective clinical efficacy in patients with lung cancer. A variety of therapeutic drugs, including oncolytic adenovirus, chemotherapeutic drugs, nucleic acids, antibodies, and antigens, have been carried to the targeted area for corresponding tumor treatment. ${ }^{157}$ Autologous tumor-cell-derived MVs packaged with chemotherapeutic agents have been approved as a new biologic therapy for the treatment of malignant tumors after proving to be safe and well-tolerated. ${ }^{157}$

Ran et $\mathrm{al}^{17}$ found that TMVs were a good carrier system that could deliver oncolytic adenovirus to tumors and induced highly efficient cytolysis. This delivery of oncolytic adenovirus by TMVs had various advantages. First, it avoided the host to develop antiviral effects. Second, it was highly efficient, because the entry of the virus into tumor cells was not limited by the need for a virus-specific receptor. Finally, TMVs could 
deliver oncolytic adenovirus to the nucleus of tumor cells and stem-like TRCs. Saari et al ${ }^{158}$ clarified that MVs derived from prostate cancer cells could be used as carriers of paclitaxel, delivering drugs to the recipient cells via endocytosis, with an increased cytotoxic effect. Krishnan et $\mathrm{al}^{159}$ reported that the levels and phenotypes of $\mathrm{CD} 138^{+} / \mathrm{CD} 41 \mathrm{a}^{-}$MVs originating from multiple myeloma could be used as indicators of disease state and therapeutic outcomes in multiple myeloma patients. Their study demonstrated that TMV could be used as a novel prognostic biomarker to monitor malignant cells. Chen et al ${ }^{160}$ proposed a donor-cell-assisted membrane biotinylation strategy to achieve biocompatible quantum dot labeling of TMVs. By further encapsulation with small interfering RNAs, the TMVs were converted into intercellular mediators as functionalized carriers for combined bioimaging and tumor-targeted therapy. Their investigation may have changed the field with the analysis and application of TMVs and provided a novel idea for the preparation of nanocarriers (Figure 3).

\section{Conclusion and Perspective}

MVs are special extracellular vesicles that are widely present in various body fluids. Many factors increase the number of MVs shed from cells, including hypoxia, irradiation, chemotherapy, and cell activation. ${ }^{34,154,161} \mathrm{MVs}$ carry large amounts of biological information that can be acquired by non-invasive technology; thus, they have broad applications as clinical tumor biomarkers. Both normal cells and malignant tumor cells can produce MVs; however, the numbers and nature of the MVs are different, and the biomarkers are also distinct. The protein molecules contained in MVs may reflect the molecular properties of the tumor cells from which they originate; therefore, they can be used as prognostic factors for TNM stage and response to therapy.

Owing to their phospholipid bilayer structure, MVs can fuse with the target cell membrane and thus transport antitumor drugs into cells. Therefore, MVs with targeted

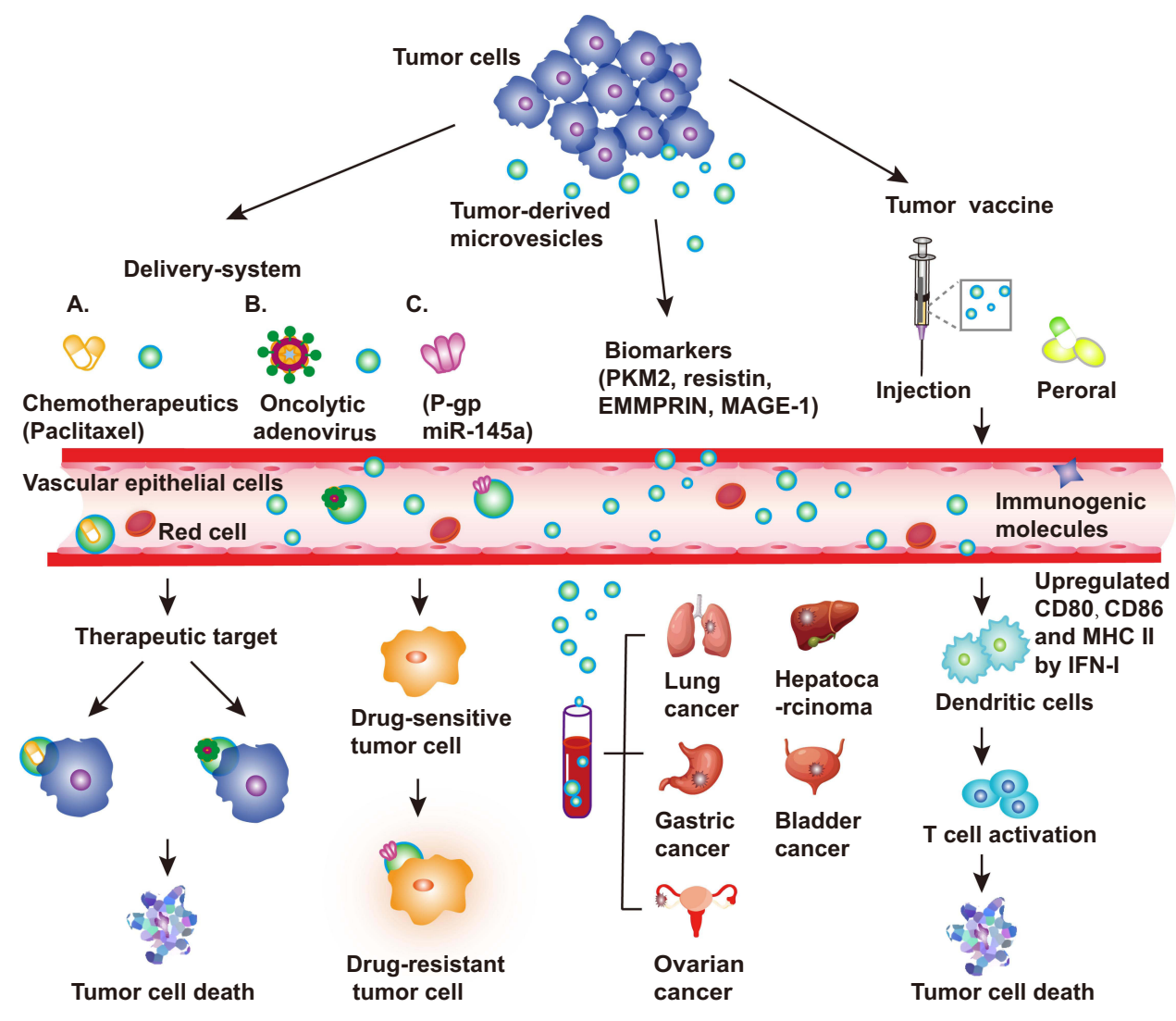

Figure 3 Applications of tumor-derived microvesicles (TMVs). TMVs are released by tumor cells in the tumor microenvironment (TME). TMVs can be used as a delivery system, for instance, carrying chemotherapeutic drugs (paclitaxel), oncolytic adenovirus, P-gp, or miR-145a to the target area for cancer treatment. TMVs carrying P-gP reverse the drug resistance of tumor cells. Owing to their stability, TMVs can provide diagnostic information when extracted from body fluids of cancer patients, including patients with lung cancer, hepatocarcinoma, gastric cancer, and ovarian cancer. Examples of markers include PKM2, resistin, EMMPRIN, and MAGE-I. TMVs can carry a variety of immunogenic molecules, including proteins, nucleic acids, and polysaccharides. TMVs can transfer antigens or innate signals (DNA or others) to dendritic cells (DC); then, the armed DCs activate tumor-specific T cells, resulting in the lysis of tumor cells.

Abbreviations: PKM2, pyruvate kinase M2; EMMPRIN, extracellular matrix metalloproteinase inducer. 
properties may be good carriers for anti-tumor therapies. Local invasion and distant metastasis are important factors associated with poor prognosis in patients with malignancy. MVs can be used as carriers to carry biological signals or molecules that promote invasion and metastasis of tumor cells and can serve as biomarkers to predict the prognosis of cancer patients. Although MVs have broad application as biomarkers, there are still some challenges to be resolved. For example, the release of MVs may be affected by age, infection, and inflammation. In addition, the sensitivity of detection is a major obstacle in the development of tumor-specific markers. ${ }^{162}$ The diameters of exosomes range from 40 to $160 \mathrm{~nm},{ }^{120}$ whereas MV have diameters ranging from 100 to $1000 \mathrm{~nm}$; thus, exosomes overlap with MVs in terms of size. Therefore, studies should carefully distinguish between exosomes and MVs. So far, methods for isolation of MVs have been based on primary centrifugation, which collects the supernatant to abolish cell fragments. This is followed by separation of cellfree extracts using size-exclusion chromatography, filtration, precipitation, magnetophoretic sorting, and immunoaffinity chromatography. However, there is still a need for highefficiency methods to be developed. In particular, the current methods for isolation of MVs pose obstacles to achieving clinical-grade quality.

MVs serve as mediators of intercellular communication by delivering components to target cells, thereby modifying phenotypes and reprogramming cell function. Therefore, it is worth exploring the effects of MV-mediated intercellular communication on tumor progression. Tumor vaccines related to exosomes, including ascitic cell-derived exosome vaccines and DC-derived exosome vaccines, have entered Phase I clinical trials and are expected to show excellent results. ${ }^{163-165}$ However, there are no TMV vaccines currently moving to clinical trials.

\section{Abbreviations}

MVs, microvesicles; MMPs, matrix metalloproteinases; ARF6, ADP-ribosylation factor 6; TMVs, tumor-derived microvesicles; TME, the tumor microenvironment; CAFs, cancer-associated fibroblasts; ECM, extracellular matrix components; miRNAs, microRNAs; MLCK, myosin lightchain kinase; MLC, myosin II light chain; ERK, extracellular signal-regulated kinases; ELISA, Enzyme-linked immunosorbent assay; EGFRvIII, epidermal growth factor receptor variant III; EMT, epithelial-mesenchymal transition; EMMPRIN, extracellular matrix metalloproteinase inducer; APCs, antigen-presenting cells; FasL, Fas ligand; HSPCs, hematopoietic stem and progenitor cells; L-MPs, lung cancer microparticles; MAPK, mitogen-activated protein kinase; MHC I, major histocompatibility complex I; CCR6, CC chemokine receptor 6; VEGF, vascular endothelial growth factor; IL-8, interleukin-8; TNF, tumor necrosis factor; TF, tissue factor; ILVs, intraluminal vesicles; MVB, multivesicular body; ESCRT, endosomal-sorting complex required for transport; CD9, cluster of differentiation 9; CD63, cluster of differentiation 63; CD81, cluster of differentiation 81; LOs, large oncosomes; IFN- $\gamma$, interferon- $\gamma$; AECs, alveolar epithelial cells; DCs, dendritic cells; TGF- $\beta$, transforming growth factor-beta; GBM, glioblastoma; MDSCs, myeloid-derived suppressor cells; NK cells, natural killer cells; CCL2, CC chemokine ligand 2; MDR, multidrug resistance; P-gp, P-glycoprotein; TRPC5, transient receptor potential channel 5; HMECs, human mammary epithelial cells; ALL, acute lymphoblastic leukemia; 5-FU, 5-Fluorouracil; IECs, ileal epithelial cells; IFN-I, interferon I; IR-MVs, irradiated C6 cell-derived MVs; GPI, glycosylphosphatidylinositol; mAb, monoclonal antibody; HNSCC, head and neck squamous cell carcinoma; PKM2, pyruvate kinase M2; HCC, hepatocellular carcinoma; SMVs, saliva MVs; OSCC, oral squamous cell carcinoma; TRCs, tumor repopulating cells.

\section{Funding}

This work was supported by the National Natural Science Foundation of China (No. 81874120, No. 82073370).

\section{Disclosure}

The authors report no conflicts of interest in this work.

\section{References}

1. van Niel G, D'Angelo G, Raposo G. Shedding light on the cell biology of extracellular vesicles. Nat Rev Mol Cell Biol. 2018;19(4):213-228. doi: $10.1038 / \mathrm{nrm} .2017 .125$

2. O’Brien K, Breyne K, Ughetto S, Laurent LC, Breakefield XO. RNA delivery by extracellular vesicles in mammalian cells and its applications. Nat Rev Mol Cell Biol. 2020;21(10):585-606.

3. Li S, Yi M, Dong B, Jiao Y, Luo S, Wu K. The roles of exosomes in cancer drug resistance and its therapeutic application. Clin Transl Med. 2020;10(8):e257. doi:10.1002/ctm2.257

4. Menck K, Scharf C, Bleckmann A, et al. Tumor-derived microvesicles mediate human breast cancer invasion through differentially glycosylated EMMPRIN. J Mol Cell Biol. 2015;7(2):143-153.

5. Ortiz A. Not all extracellular vesicles were created equal: clinical implications. Ann Transl Med. 2017;5(5):111. doi:10.21037/ atm.2017.01.40

6. Mathew M, Zade M, Mezghani N, Patel R, Wang Y, Momen-Heravi F. Extracellular vesicles as biomarkers in cancer immunotherapy. Cancers. 2020;12:10.

7. Minciacchi V, Freeman M, Di Vizio DJ. Extracellular vesicles in cancer: exosomes, microvesicles and the emerging role of large oncosomes. Semin Cell Dev Biol. 2015;40:41-51. doi:10.1016/j. semcdb.2015.02.010 
8. Agrahari V, Agrahari V, Burnouf $\mathrm{P}$, Chew $\mathrm{C}$, Burnouf $\mathrm{T}$. Extracellular microvesicles as new industrial therapeutic frontiers. Trends Biotechnol. 2019;37(7):707-729. doi:10.1016/j. tibtech.2018.11.012

9. Stahl PD, Raposo G. Extracellular vesicles: exosomes and microvesicles, integrators of homeostasis. Physiology. 2019;34 (3):169-177.

10. Clancy JW, Zhang Y, Sheehan C, D'Souza-Schorey C. An ARF6-Exportin-5 axis delivers pre-miRNA cargo to tumour microvesicles. Nat Cell Biol. 2019;21(7):856-866. doi:10.1038/ s41556-019-0345-y

11. D'Souza-Schorey C, Clancy JW. Tumor-derived microvesicles: shedding light on novel microenvironment modulators and prospective cancer biomarkers. Genes Dev. 2012;26(12):1287-1299. doi:10.1101/gad.192351.112

12. Fetah KL, DiPardo BJ, Kongadzem EM, et al. Cancer modeling-on-a-chip with future artificial intelligence integration. Small. 2019;15(50):e1901985. doi:10.1002/smll.201901985

13. Belli C, Trapani D, Viale G, et al. Targeting the microenvironment in solid tumors. Cancer Treat Rev. 2018;65:22-32. doi:10.1016/j.ctrv.2018.02.004

14. Bian X, Xiao YT, Wu T, et al. Microvesicles and chemokines in tumor microenvironment: mediators of intercellular communications in tumor progression. Mol Cancer. 2019;18(1):50. doi:10.1186/s12943-019-0973-7

15. Willms E, Cabañas C, Mäger I, Wood MJA, Vader P. Extracellular vesicle heterogeneity: subpopulations, isolation techniques, and diverse functions in cancer progression. Front Immunol. 2018;9:738. doi:10.3389/fimmu.2018.00738

16. Ma J, Zhang H, Tang K, Huang B. Tumor-derived microparticles in tumor immunology and immunotherapy. Eur J Immunol. 2020;50(11):1653-1662. doi:10.1002/eji.202048548

17. Ran L, Tan X, Li Y, et al. Delivery of oncolytic adenovirus into the nucleus of tumorigenic cells by tumor microparticles for virotherapy. Biomaterials. 2016;89:56-66. doi:10.1016/j. biomaterials.2016.02.025

18. Friend C, Marovitz W, Henie G, et al. Observations on cell lines derived from a patient with Hodgkin's disease. Cancer Res. 1978;38(8):2581-2591.

19. Poste G, Nicolson GL. Arrest and metastasis of blood-borne tumor cells are modified by fusion of plasma membrane vesicles from highly metastatic cells. Proc Natl Acad Sci USA. 1980;77 (1):399-403. doi:10.1073/pnas.77.1.399

20. Lee CH, Im EJ, Moon PG, Baek MC. Discovery of a diagnostic biomarker for colon cancer through proteomic profiling of small extracellular vesicles. BMC Cancer. 2018;18(1):1058. doi:10.1186/s12885-018-4952-y

21. Pap E, Pállinger E, Pásztói M, Falus A. Highlights of a new type of intercellular communication: microvesicle-based information transfer. Inflamm Res. 2009;58(1):1-8. doi:10.1007/s00011-008-8210-7

22. Piccin A, Murphy WG, Smith OP. Circulating microparticles: pathophysiology and clinical implications. Blood Rev. 2007;21 (3):157-171. doi:10.1016/j.blre.2006.09.001

23. Inal JM, Ansa-Addo EA, Stratton D, et al. Microvesicles in health and disease. Arch Immunol Ther Exp. 2012;60(2):107-121. doi:10.1007/s00005-012-0165-2

24. Jorfi S, Inal JM. The role of microvesicles in cancer progression and drug resistance. Biochem Soc Trans. 2013;41(1):293-298. doi:10.1042/BST20120273

25. Muralidharan-Chari V, Clancy J, Plou C, et al. ARF6-regulated shedding of tumor cell-derived plasma membrane microvesicles. Curr Biol. 2009;19(22):1875-1885. doi:10.1016/j.cub.2009.09.059

26. Wang D, Sun W. Urinary extracellular microvesicles: isolation methods and prospects for urinary proteome. Proteomics. 2014;14 (16):1922-1932. doi:10.1002/pmic.201300371
27. Johnson DL, Wayt J, Wilson JM, Donaldson JG. Arf6 and Rab22 mediate $T$ cell conjugate formation by regulating clathrin-independent endosomal membrane trafficking. J Cell Sci. 2017;130 (14):2405-2415.

28. Tricarico C, Clancy J, D’Souza-Schorey C. Biology and biogenesis of shed microvesicles. Small GTPases. 2017;8(4):220-232. doi:10.1080/21541248.2016.1215283

29. D'Souza-Schorey C, Chavrier P. ARF proteins: roles in membrane traffic and beyond. Nat Rev Mol Cell Biol. 2006;7 (5):347-358. doi:10.1038/nrm1910

30. Donaldson JG. Multiple roles for Arf6: sorting, structuring, and signaling at the plasma membrane. J Biol Chem. 2003;278 (43):41573-41576. doi:10.1074/jbc.R300026200

31. Sobieszek A, Strobl A, Ortner B, Babiychuk EB. Ca(2+)-calmodulindependent modification of smooth-muscle myosin light-chain kinase leading to its co-operative activation by calmodulin. Biochem J. 1993;295(Pt 2):405-411. doi:10.1042/bj2950405

32. Mentkowski KI, Snitzer JD, Rusnak S, Lang JK. Therapeutic potential of engineered extracellular vesicles. AAPS J. 2018;20 (3):50. doi:10.1208/s12248-018-0211-z

33. Weigert R, Donaldson JG. Fluorescent microscopy-based assays to study the role of Rab22a in clathrin-independent endocytosis. Methods Enzymol. 2005;403:243-253.

34. Wang T, Gilkes DM, Takano N, et al. Hypoxia-inducible factors and RAB22A mediate formation of microvesicles that stimulate breast cancer invasion and metastasis. Proc Natl Acad Sci USA. 2014;111(31):E3234-3242. doi:10.1073/ pnas.1410041111

35. Li B, Antonyak MA, Zhang J, Cerione RA. RhoA triggers a specific signaling pathway that generates transforming microvesicles in cancer cells. Oncogene. 2012;31(45):4740-4749. doi:10.1038/onc.2011.636

36. Sedgwick AE, Clancy JW, Olivia Balmert M, D’Souza-Schorey C. Extracellular microvesicles and invadopodia mediate non-overlapping modes of tumor cell invasion. Sci Rep. 2015;5 (1):14748. doi: $10.1038 /$ srep 14748

37. Schlienger S, Campbell S, Claing A. ARF1 regulates the Rho/ MLC pathway to control EGF-dependent breast cancer cell invasion. Mol Biol Cell. 2014;25(1):17-29. doi:10.1091/mbc. e13-06-0335

38. Zhong WD, Liang YX, Lin SX, et al. Expression of CD147 is associated with prostate cancer progression. Int $J$ Cancer. 2012;130(2):300-308. doi:10.1002/ijc. 25982

39. Sheehan C, D'Souza-Schorey C. Tumor-derived extracellular vesicles: molecular parcels that enable regulation of the immune response in cancer. $J$ Cell Sci. 2019;132(20):jcs235085. doi:10.1242/jcs. 235085

40. Koga K, Nabeshima K, Aoki M, et al. Emmprin in epithelioid sarcoma: expression in tumor cell membrane and stimulation of MMP-2 production in tumor-associated fibroblasts. Int J Cancer. 2007;120(4):761-768. doi:10.1002/ijc.22412

41. Skog J, Würdinger T, van Rijn S, et al. Glioblastoma microvesicles transport RNA and proteins that promote tumour growth and provide diagnostic biomarkers. Nat Cell Biol. 2008;10 (12):1470-1476. doi:10.1038/ncb1800

42. Rak J. Microparticles in cancer. Semin Thromb Hemost. 2010;36 (8):888-906. doi:10.1055/s-0030-1267043

43. Lo Cicero A, Schiera G, Proia P, et al. Oligodendroglioma cells shed microvesicles which contain TRAIL as well as molecular chaperones and induce cell death in astrocytes. Int $J$ Oncol. 2011;39(6):1353-1357.

44. Muralidharan-Chari V, Clancy JW, Sedgwick A, D'SouzaSchorey C. Microvesicles: mediators of extracellular communication during cancer progression. J Cell Sci. 2010;123(Pt 10):1603-1611. doi:10.1242/jcs.064386 
45. Nabeshima K, Iwasaki H, Koga K, Hojo H, Suzumiya J, Kikuchi M. Emmprin (basigin/CD147): matrix metalloproteinase modulator and multifunctional cell recognition molecule that plays a critical role in cancer progression. Pathol Int. 2006;56 (7):359-367. doi:10.1111/j.1440-1827.2006.01972.x

46. Aoki M, Koga K, Hamasaki M, Egawa N, Nabeshima K. Emmprin, released as a microvesicle in epithelioid sarcoma, interacts with fibroblasts. Int $J$ Oncol. 2017;50(6):2229-2235. doi:10.3892/ijo.2017.3986

47. Giusti I, D’Ascenzo S, Dolo V. Microvesicles as potential ovarian cancer biomarkers. Biomed Res Int. 2013;2013:703048. doi:10.1155/2013/703048

48. Witwer KW, Buzás EI, Bemis LT, et al. Standardization of sample collection, isolation and analysis methods in extracellular vesicle research. J Extracell Vesicles. 2013;2(1):20360. doi:10.3402/jev. $\mathrm{v} 2 \mathrm{i} 0.20360$

49. Gelderman MP, Simak J. Flow cytometric analysis of cell membrane microparticles. Methods Mol Biol. 2008;484:79-93.

50. Lukacs-Kornek V, Julich-Haertel H, Urban SK, Kornek M. Multisurface antigen staining of larger extracellular vesicles. Methods Mol Biol. 2017;1660:201-208.

51. Nannan L, Oudart JB, Monboisse JC, Ramont L, Brassart-Pasco S, Brassart B. Extracellular vesicle-dependent cross-talk in cancer-focus on pancreatic cancer. Front Oncol. 2020;10:1456. doi: $10.3389 /$ fonc. 2020.01456

52. Baj-Krzyworzeka M, Szatanek R, Weglarczyk K, et al. Tumourderived microvesicles carry several surface determinants and mRNA of tumour cells and transfer some of these determinants to monocytes. Cancer Immunol Immunother. 2006;55 (7):808-818. doi:10.1007/s00262-005-0075-9

53. Kim CW, Lee HM, Lee TH, Kang C, Kleinman HK, Gho YS. Extracellular membrane vesicles from tumor cells promote angiogenesis via sphingomyelin. Cancer Res. 2002;62(21):6312-6317.

54. van Rooij N, van Buuren MM, Philips D, et al. Tumor exome analysis reveals neoantigen-specific T-cell reactivity in an ipilimumab-responsive melanoma. J Clin Oncol. 2013;31(32): e439-442. doi:10.1200/JCO.2012.47.7521

55. Giebel B, Wodarz A. Tumor suppressors: control of signaling by endocytosis. Curr Biol. 2006;16(3):R91-R92. doi:10.1016/j. cub.2006.01.022

56. Valenti R, Huber V, Iero M, Filipazzi P, Parmiani G, Rivoltini L. Tumor-released microvesicles as vehicles of immunosuppression. Cancer Res. 2007;67(7):2912-2915. doi:10.1158/0008-5472. CAN-07-0520

57. Al-Nedawi K, Meehan B, Micallef J, et al. Intercellular transfer of the oncogenic receptor EGFRvIII by microvesicles derived from tumour cells. Nat Cell Biol. 2008;10(5):619-624. doi:10.1038/ ncb1725

58. De Palma M, Biziato D, Petrova TV. Microenvironmental regulation of tumour angiogenesis. Nat Rev Cancer. 2017;17 (8):457-474. doi:10.1038/nrc.2017.51

59. Zhang H, Bai M, Deng T, et al. Cell-derived microvesicles mediate the delivery of miR-29a/c to suppress angiogenesis in gastric carcinoma. Cancer Lett. 2016;375(2):331-339. doi:10.1016/j. canlet.2016.03.026

60. Al-Nedawi K, Meehan B, Kerbel RS, Allison AC, Rak J. Endothelial expression of autocrine VEGF upon the uptake of tumor-derived microvesicles containing oncogenic EGFR. Proc Natl Acad Sci USA. 2009;106(10):3794-3799. doi:10.1073/ pnas.0804543106

61. Szubert S, Szpurek D, Moszynski R, et al. Extracellular matrix metalloproteinase inducer (EMMPRIN) expression correlates positively with active angiogenesis and negatively with basic fibroblast growth factor expression in epithelial ovarian cancer. $J$ Cancer Res Clin Oncol. 2014;140(3):361-369. doi:10.1007/ s00432-013-1569-z
62. Finley SD, Popel AS. Effect of tumor microenvironment on tumor VEGF during anti-VEGF treatment: systems biology predictions. $J$ Natl Cancer Inst. 2013;105(11):802-811. doi:10.1093/jnci/djt093

63. Osterud B. The role of platelets in decrypting monocyte tissue factor. Semin Hematol. 2001;38(4 Suppl 12):2-5. doi:10.1016/ S0037-1963(01)90139-8

64. Geddings JE, Hisada Y, Boulaftali Y, et al. Tissue factor-positive tumor microvesicles activate platelets and enhance thrombosis in mice. J Thromb Haemost. 2016;14(1):153-166. doi:10.1111/ jth.13181

65. Pan Y, Yu Y, Wang X, Zhang T. Tumor-associated macrophages in tumor Immunity. Front Immunol. 2020;11:583084. doi:10.3389/fimmu.2020.583084

66. Zhao S, Mi Y, Guan B, et al. Tumor-derived exosomal miR-934 induces macrophage M2 polarization to promote liver metastasis of colorectal cancer. J Hematol Oncol. 2020;13(1):156. doi:10.1186/s13045-020-00991-2

67. Ma R, Ji T, Chen D, et al. Tumor cell-derived microparticles polarize M2 tumor-associated macrophages for tumor progression. Oncoimmunology. 2016;5(4):e1118599. doi:10.1080/2162402X.2015.1118599

68. Vanaja SK, Rathinam VA, Fitzgerald KA. Mechanisms of inflammasome activation: recent advances and novel insights. Trends Cell Biol. 2015;25(5):308-315. doi:10.1016/j.tcb.2014.12.009

69. Gupta P, Barthwal MK. IL-1 $\beta$ genesis: the art of regulating the regulator. Cell Mol Immunol. 2018;15(11):998-1000. doi:10.1038/s41423-018-0054-7

70. West NR, McCuaig S, Franchini F, Powrie F. Emerging cytokine networks in colorectal cancer. Nat Rev Immunol. 2015;15 (10):615-629. doi:10.1038/nri3896

71. Chen J, Sun W, Zhang H, et al. Macrophages reprogrammed by lung cancer microparticles promote tumor development via release of IL-1ß. Cell Mol Immunol. 2020;17(12):1233-1244. doi:10.1038/s41423-019-0313-2

72. Dionisi M, De Archangelis C, Battisti F, et al. Tumor-derived microvesicles enhance cross-processing ability of clinical grade dendritic cells. Front Immunol. 2018;9:2481. doi:10.3389/ fimmu.2018.02481

73. Valenti R, Huber V, Filipazzi P, et al. Human tumor-released microvesicles promote the differentiation of myeloid cells with transforming growth factor-beta-mediated suppressive activity on T lymphocytes. Cancer Res. 2006;66(18):9290-9298. doi:10.1158/0008-5472.CAN-06-1819

74. Szajnik M, Czystowska M, Szczepanski MJ, Mandapathil M, Whiteside TL. Tumor-derived microvesicles induce, expand and up-regulate biological activities of human regulatory $\mathrm{T}$ cells (Treg). PLoS One. 2010;5(7):e11469.

75. Taylor DD, Gerçel-Taylor C, Lyons KS, Stanson J, Whiteside TL. T-cell apoptosis and suppression of T-cell receptor/CD3-zeta by Fas ligand-containing membrane vesicles shed from ovarian tumors. Clin Cancer Res. 2003;9(14):5113-5119.

76. Poulaki V, Mitsiades CS, Mitsiades N. The role of Fas and FasL as mediators of anticancer chemotherapy. Drug Resist Updat. 2001;4(4):233-242. doi:10.1054/drup.2001.0210

77. Ju ST, Panka DJ, Cui H, et al. Fas(CD95)/FasL interactions required for programmed cell death after T-cell activation. Nature. 1995;373(6513):444-448. doi:10.1038/373444a0

78. Kim JW, Wieckowski E, Taylor DD, Reichert TE, Watkins S, Whiteside TL. Fas ligand-positive membranous vesicles isolated from sera of patients with oral cancer induce apoptosis of activated T lymphocytes. Clin Cancer Res. 2005;11(3):1010-1020.

79. Wieckowski E, Whiteside TL. Human tumor-derived vs dendritic cell-derived exosomes have distinct biologic roles and molecular profiles. Immunol Res. 2006;36(1-3):247-254. doi:10.1385/ IR:36:1:247 
80. Huber V, Fais S, Iero M, et al. Human colorectal cancer cells induce T-cell death through release of proapoptotic microvesicles: role in immune escape. Gastroenterology. 2005;128 (7):1796-1804. doi:10.1053/j.gastro.2005.03.045

81. Andreola G, Rivoltini L, Castelli C, et al. Induction of lymphocyte apoptosis by tumor cell secretion of FasL-bearing microvesicles. $J$ Exp Med. 2002;195(10):1303-1316. doi:10.1084/jem.20011624

82. Yi M, Xu L, Jiao Y, Luo $\mathrm{S}$, Li A, Wu K. The role of cancer-derived microRNAs in cancer immune escape. J Hematol Oncol. 2020;13(1):25. doi:10.1186/s13045-020-00848-8

83. Cui J, Li Q, Luo M, et al. Leukemia cell-derived microvesicles induce T cell exhaustion via miRNA delivery. Oncoimmunology. 2018;7(7):e1448330. doi:10.1080/2162402X.2018.1448330

84. Angelucci A, D’Ascenzo S, Festuccia C, et al. Vesicle-associated urokinase plasminogen activator promotes invasion in prostate cancer cell lines. Clin Exp Metastasis. 2000;18(2):163-170. doi:10.1023/A:1006778000173

85. Graves LE, Ariztia EV, Navari JR, Matzel HJ, Stack MS, Fishman DA. Proinvasive properties of ovarian cancer ascites-derived membrane vesicles. Cancer Res. 2004;64 (19):7045-7049. doi:10.1158/0008-5472.CAN-04-1800

86. Taraboletti G, D’Ascenzo S, Borsotti P, Giavazzi R, Pavan A, Dolo V. Shedding of the matrix metalloproteinases MMP-2, MMP-9, and MT1-MMP as membrane vesicle-associated components by endothelial cells. Am J Pathol. 2002;160(2):673-680. doi:10.1016/S0002-9440(10)64887-0

87. Wortzel I, Dror S, Kenific CM, Lyden D. Exosome-mediated metastasis: communication from a distance. Dev Cell. 2019;49 (3):347-360. doi:10.1016/j.devcel.2019.04.011

88. Arshad Malik MF. Influence of microvesicles in breast cancer metastasis and their therapeutic implications. Arch Iran Med. 2015;18(3):189-192.

89. Pap E, Pállinger E, Falus A. The role of membrane vesicles in tumorigenesis. Crit Rev Oncol Hematol. 2011;79(3):213-223. doi:10.1016/j.critrevonc.2010.07.015

90. Grange C, Tapparo M, Collino F, et al. Microvesicles released from human renal cancer stem cells stimulate angiogenesis and formation of lung premetastatic niche. Cancer Res. 2011;71 (15):5346-5356. doi:10.1158/0008-5472.CAN-11-0241

91. Zhang H, Yu Y, Zhou L, et al. Circulating tumor microparticles promote lung metastasis by reprogramming inflammatory and mechanical niches via a macrophage-dependent pathway. Cancer Immunol Res. 2018;6(9):1046-1056. doi:10.1158/23266066.CIR-17-0574

92. Pfeiler S, Thakur M, Grünauer P, et al. CD36-triggered cell invasion and persistent tissue colonization by tumor microvesicles during metastasis. FASEB J. 2019;33(2):1860-1872. doi:10.1096/ fj.201800985R

93. Gieseler F, Plattfaut C, Quecke T, Freund A, Ungefroren H, Ender F. Heterogeneity of microvesicles from cancer cell lines under inflammatory stimulation with TNF- $\alpha$. Cell Biol Int. 2018;42(11):1533-1544. doi:10.1002/cbin.11040

94. Antonyak MA, Li B, Boroughs LK, et al. Cancer cell-derived microvesicles induce transformation by transferring tissue transglutaminase and fibronectin to recipient cells. Proc Natl Acad Sci USA. 2011;108(12):4852-4857. doi:10.1073/pnas.1017667108

95. Castellana D, Zobairi F, Martinez MC, et al. Membrane microvesicles as actors in the establishment of a favorable prostatic tumoral niche: a role for activated fibroblasts and CX3CL1-CX3CR1 axis. Cancer Res. 2009;69(3):785-793. doi:10.1158/0008-5472.CAN-08-1946

96. Pokharel D, Padula MP, Lu JF, et al. Proteome analysis of multidrug-resistant, breast cancer-derived microparticles. J Extracell Vesicles. 2014;3(1):24384. doi:10.3402/jev.v3.24384
97. Namee NM, O’Driscoll L. Extracellular vesicles and anti-cancer drug resistance. Biochim Biophys Acta Rev Cancer. 2018;1870 (2):123-136. doi:10.1016/j.bbcan.2018.07.003

98. Rajeev Krishnan S, De Rubis G, Suen H, Joshua D, Lam Kwan Y, Bebawy M. A liquid biopsy to detect multidrug resistance and disease burden in multiple myeloma. Blood Cancer J. 2020;10 (3):37. doi:10.1038/s41408-020-0304-7

99. Gong J, Jaiswal R, Mathys JM, Combes V, Grau GE, Bebawy M. Microparticles and their emerging role in cancer multidrug resistance. Cancer Treat Rev. 2012;38(3):226-234. doi:10.1016/ j.ctrv.2011.06.005

100. Ma X, Cai Y, He D, et al. Transient receptor potential channel TRPC5 is essential for P-glycoprotein induction in drug-resistant cancer cells. Proc Natl Acad Sci USA. 2012;109 (40):16282-16287. doi:10.1073/pnas.1202989109

101. Dong Y, Pan Q, Jiang L, et al. Tumor endothelial expression of P-glycoprotein upon microvesicular transfer of TrpC5 derived from Adriamycin-resistant breast cancer cells. Biochem Biophys Res Commun. 2014;446(1):85-90. doi:10.1016/j. bbrc.2014.02.076

102. Bebawy M, Combes V, Lee E, et al. Membrane microparticles mediate transfer of P-glycoprotein to drug sensitive cancer cells. Leukemia. 2009;23(9):1643-1649. doi:10.1038/leu.2009.76

103. Zhang FF, Zhu YF, Zhao QN, et al. Microvesicles mediate transfer of P-glycoprotein to paclitaxel-sensitive A2780 human ovarian cancer cells, conferring paclitaxel-resistance. Eur J Pharmacol. 2014;738:83-90. doi:10.1016/j.ejphar.2014.05.026

104. Dong B, Li S, Zhu S, Yi M, Luo S, Wu K. MiRNA-mediated EMT and CSCs in cancer chemoresistance. Exp Hematol Oncol. 2021;10(1):12. doi:10.1186/s40164-021-00206-5

105. Klümper T, Bruckmueller H, Diewock T, et al. Expression differences of miR-142-5p between treatment-naïve chronic myeloid leukemia patients responding and non-responding to imatinib therapy suggest a link to oncogenic ABL2, SRI, cKIT and MCL1 signaling pathways critical for development of therapy resistance. Exp Hematol Oncol. 2020;9:26.

106. Akao Y, Khoo F, Kumazaki M, Shinohara H, Miki K, Yamada N. Extracellular disposal of tumor-suppressor miRs-145 and $-34 \mathrm{a}$ via microvesicles and 5-FU resistance of human colon cancer cells. Int $J$ Mol Sci. 2014;15(1):1392-1401. doi:10.3390/ ijms 15011392

107. Ratajczak J, Wysoczynski M, Hayek F, Janowska-Wieczorek A, Ratajczak MZ. Membrane-derived microvesicles: important and underappreciated mediators of cell-to-cell communication. Leukemia. 2006;20(9):1487-1495. doi:10.1038/sj.leu.2404296

108. Melzani G, Bugari G, Parrinello G, Mori G, Manganoni A, De Panfilis G. Evaluation of soluble Fas ligand as a serological marker for melanoma. Dermatology. 2002;205(2):111-115. doi:10.1159/000063894

109. Samii A, Razmkhah F. Transformation of hematopoietic stem and progenitor cells by leukemia extracellular vesicles: a step toward leukemogenesis. Stem Cell Rev Rep. 2020;16(6):1081-1091. doi:10.1007/s12015-020-09975-8

110. Fulci V, Chiaretti S, Goldoni M, et al. Quantitative technologies establish a novel microRNA profile of chronic lymphocytic leukemia. Blood. 2007;109(11):4944-4951. doi:10.1182/blood2006-12-062398

111. Lawrie $\mathrm{CH}$, Soneji S, Marafioti T, et al. MicroRNA expression distinguishes between germinal center B cell-like and activated B cell-like subtypes of diffuse large B cell lymphoma. Int J Cancer. 2007;121(5):1156-1161. doi:10.1002/ijc.22800

112. Pichiorri F, Suh SS, Ladetto M, et al. MicroRNAs regulate critical genes associated with multiple myeloma pathogenesis. Proc Natl Acad Sci USA. 2008;105(35):12885-12890. doi:10.1073/ pnas.0806202105 
113. Razmkhah F, Soleimani M, Mehrabani D, et al. Leukemia microvesicles affect healthy hematopoietic stem cells. Tumour Biol. 2017;39(2):1010428317692234. doi:10.1177/ 1010428317692234

114. Le MT, Hamar P, Guo C, et al. miR-200-containing extracellular vesicles promote breast cancer cell metastasis. J Clin Invest. 2014;124(12):5109-5128. doi:10.1172/JCI75695

115. Gould SJ, Raposo G. As we wait: coping with an imperfect nomenclature for extracellular vesicles. J Extracell Vesicles. 2013;2(1):20389. doi:10.3402/jev.v2i0.20389

116. Möller A, Lobb RJ. The evolving translational potential of small extracellular vesicles in cancer. Nat Rev Cancer. 2020;20 (12):697-709. doi:10.1038/s41568-020-00299-w

117. Bebelman MP, Smit MJ, Pegtel DM, Baglio SR. Biogenesis and function of extracellular vesicles in cancer. Pharmacol Ther. 2018;188:1-11. doi:10.1016/j.pharmthera.2018.02.013

118. Kim KM, Abdelmohsen K, Mustapic M, Kapogiannis D, Gorospe M. RNA in extracellular vesicles. Wiley Interdiscip Rev RNA. 2017;8(4):e1413. doi:10.1002/wrna.1413

119. Zhu L, Sun HT, Wang S, et al. Isolation and characterization of exosomes for cancer research. J Hematol Oncol. 2020;13(1):152.

120. Li S, Yi M, Dong B, Tan X, Luo S, Wu K. The role of exosomes in liquid biopsy for cancer diagnosis and prognosis prediction. Int J Cancer. 2021;148(11):2640-2651. doi:10.1002/ijc.33386

121. Wang H, Lu Z, Zhao X. Tumorigenesis, diagnosis, and therapeutic potential of exosomes in liver cancer. J Hematol Oncol. 2019;12(1):133. doi:10.1186/s13045-019-0806-6

122. Matarredona ER, Pastor AM. Extracellular vesicle-mediated communication between the Glioblastoma and its microenvironment. Cells. 2019;9(1):96. doi:10.3390/cells9010096

123. Wu Z, Wang L, Li J, Wang L, Wu Z, Sun X. Extracellular vesicle-mediated communication within host-parasite interactions. Front Immunol. 2018;9:3066. doi:10.3389/ fimmu.2018.03066

124. Ela S, Mäger I, Breakefield XO, Wood MJ. Extracellular vesicles: biology and emerging therapeutic opportunities. Nat Rev Drug Discov. 2013;12(5):347-357. doi:10.1038/nrd3978

125. Yi M, Niu M, Xu L, Luo S, Wu K. Regulation of PD-L1 expression in the tumor microenvironment. J Hematol Oncol. 2021;14 (1):10. doi:10.1186/s13045-020-01027-5

126. Owen KL, Brockwell NK, Parker BS. JAK-STAT signaling: a double-edged sword of immune regulation and cancer progression. Cancers. 2019;11(12):2002. doi:10.3390/cancers11122002

127. Bourdonnay E, Zasłona Z, Penke LR, et al. Transcellular delivery of vesicular SOCS proteins from macrophages to epithelial cells blunts inflammatory signaling. J Exp Med. 2015;212(5):729-742. doi:10.1084/jem.20141675

128. Zhang H, Deng T, Liu R, et al. Exosome-delivered EGFR regulates liver microenvironment to promote gastric cancer liver metastasis. Nat Commun. 2017;8(1):15016. doi:10.1038/ ncomms 15016

129. Higginbotham JN, Demory Beckler M, Gephart JD, et al. Amphiregulin exosomes increase cancer cell invasion. Curr Biol. 2011;21(9):779-786. doi:10.1016/j.cub.2011.03.043

130. Higginbotham JN, Zhang Q, Jeppesen DK, et al. Identification and characterization of EGF receptor in individual exosomes by fluorescence-activated vesicle sorting. $J$ Extracell Vesicles. 2016;5(1):29254. doi:10.3402/jev.v5.29254

131. Gomes FG, Sandim V, Almeida VH, et al. Breast-cancer extracellular vesicles induce platelet activation and aggregation by tissue factor-independent and -dependent mechanisms. Thromb Res. 2017;159:24-32. doi:10.1016/j.thromres.2017.09.019

132. Cheng Y, Schorey JS. Exosomes carrying mycobacterial antigens can protect mice against Mycobacterium tuberculosis infection. Eur J Immunol. 2013;43(12):3279-3290. doi:10.1002/eji.201343727
133. Gaillard ME, Bottero D, Errea A, et al. Acellular pertussis vaccine based on outer membrane vesicles capable of conferring both long-lasting immunity and protection against different strain genotypes. Vaccine. 2014;32(8):931-937. doi:10.1016/j. vaccine.2013.12.048

134. Colino J, Snapper CM. Exosomes from bone marrow dendritic cells pulsed with diphtheria toxoid preferentially induce type 1 antigen-specific IgG responses in naive recipients in the absence of free antigen. J Immunol. 2006;177(6):3757-3762. doi:10.4049/ jimmunol.177.6.3757

135. György B, Hung ME, Breakefield XO, Leonard JN. Therapeutic applications of extracellular vesicles: clinical promise and open questions. Annu Rev Pharmacol Toxicol. 2015;55(1):439-464. doi:10.1146/annurev-pharmtox-010814-124630

136. Zhang Y, Zhang R, Zhang H, et al. Microparticles released by Listeria monocytogenes-infected macrophages are required for dendritic cell-elicited protective immunity. Cell Mol Immunol. 2012;9(6):489-496. doi:10.1038/cmi.2012.33

137. Dong W, Zhang H, Yin X, et al. Oral delivery of tumor microparticle vaccines activates NOD2 signaling pathway in ileac epithelium rendering potent antitumor $\mathrm{T}$ cell immunity. Oncoimmunology. 2017;6(3):e1282589. doi:10.1080/2162402X.2017.1282589

138. Zhang H, Tang K, Zhang Y, et al. Cell-free tumor microparticle vaccines stimulate dendritic cells via cGAS/STING signaling. Cancer Immunol Res. 2015;3(2):196-205. doi:10.1158/23266066.CIR-14-0177

139. Zhang H, Huang B. Tumor cell-derived microparticles: a new form of cancer vaccine. Oncoimmunology. 2015;4(8):e1017704. doi:10.1080/2162402X.2015.1017704

140. Ma J, Wei K, Zhang H, et al. Mechanisms by which dendritic cells present tumor microparticle antigens to $\mathrm{CD} 8(+) \mathrm{T}$ cells. Cancer Immunol Res. 2018;6(9):1057-1068. doi:10.1158/23266066.CIR-17-0716

141. Pineda B, Sánchez García FJ, Olascoaga NK, et al. Malignant glioma therapy by vaccination with irradiated $\mathrm{C} 6$ cell-derived microvesicles promotes an antitumoral immune response. Mol Ther. 2019;27(9):1612-1620. doi:10.1016/j.ymthe.2019.05.016

142. Parenky AC, Akalkotkar A, Mulla NS, D'Souza MJ. Harnessing T-cell activity against prostate cancer: a therapeutic microparticulate oral cancer vaccine. Vaccine. 2019;37(41):6085-6092. doi:10.1016/j.vaccine.2019.08.033

143. Pack CD, Bommireddy R, Munoz LE, et al. Tumor membrane-based vaccine immunotherapy in combination with anti-CTLA-4 antibody confers protection against immune checkpoint resistant murine triple-negative breast cancer. Hum Vaccin Immunother. 2020;16 (12):3184-3193. doi:10.1080/21645515.2020.1754691

144. Bommireddy R, Munoz LE, Kumari A, et al. Tumor membrane vesicle vaccine augments the efficacy of anti-PD1 antibody in immune checkpoint inhibitor-resistant Squamous cell carcinoma models of head and neck cancer. Vaccines. 2020;8 (2): 182 .

145. Martins VR, Dias MS, Hainaut P. Tumor-cell-derived microvesicles as carriers of molecular information in cancer. Curr Opin Oncol. 2013;25(1):66-75. doi:10.1097/ CCO.0b013e32835b7c81

146. Hou PP, Luo LJ, Chen HZ, et al. Ectosomal PKM2 promotes $\mathrm{HCC}$ by inducing macrophage differentiation and remodeling the tumor microenvironment. Mol Cell. 2020;78(6):1192-1206. e1110. doi:10.1016/j.molcel.2020.05.004

147. Smalley DM, Sheman NE, Nelson K, Theodorescu D. Isolation and identification of potential urinary microparticle biomarkers of bladder cancer. J Proteome Res. 2008;7(5):2088-2096. doi: $10.1021 /$ pr700775x

148. Hung MC, Lau YK. Basic science of HER-2/neu: a review. Semin Oncol. 1999;26(4 Suppl 12):51-59. 
149. Yu S, Liu Q, Han X, et al. Development and clinical application of anti-HER2 monoclonal and bispecific antibodies for cancer treatment. Exp Hematol Oncol. 2017;6(1):31. doi:10.1186/ s40164-017-0091-4

150. Baran J, Baj-Krzyworzeka M, Weglarczyk K, et al. Circulating tumour-derived microvesicles in plasma of gastric cancer patients. Cancer Immunol Immunother. 2010;59(6):841-850. doi:10.1007/ s00262-009-0808-2

151. Balaj L, Lessard R, Dai L, et al. Tumour microvesicles contain retrotransposon elements and amplified oncogene sequences. Nat Commun. 2011;2(1):180. doi:10.1038/ncomms1180

152. Sun Y, Huo C, Qiao Z, et al. Comparative proteomic analysis of exosomes and microvesicles in human saliva for lung cancer. $J$ Proteome Res. 2018;17(3):1101-1107. doi:10.1021/acs. jproteome. $7 \mathrm{~b} 00770$

153. Zhong WQ, Ren JG, Xiong XP, et al. Increased salivary microvesicles are associated with the prognosis of patients with oral squamous cell carcinoma. $J$ Cell Mol Med. 2019;23 (6):4054-4062. doi:10.1111/jcmm.14291

154. Sun Y, Zheng Z, Zhang H, et al. Chemotherapeutic tumor microparticles combining low-dose irradiation reprogram tumor-promoting macrophages through a tumor-repopulating cell-curtailing pathway. Oncoimmunology. 2017;6(6):e1309487. doi:10.1080/2162402X.2017.1309487

155. Ma J, Zhang Y, Tang K, et al. Reversing drug resistance of soft tumor-repopulating cells by tumor cell-derived chemotherapeutic microparticles. Cell Res. 2016;26(6):713-727. doi:10.1038/ cr.2016.53

156. Tang K, Zhang Y, Zhang H, et al. Delivery of chemotherapeutic drugs in tumour cell-derived microparticles. Nat Commun. 2012;3 (1):1282. doi:10.1038/ncomms2282

157. Zhang Z, Xiao C, Yong T, Yang X, Gan L, Li Z. Cellular microparticles for tumor targeting delivery: from bench to bedside. Chem Commun. 2020;56(46):6171-6188. doi:10.1039/ D0CC02333G

158. Saari H, Lázaro-Ibáñez E, Viitala T, Vuorimaa-Laukkanen E, Siljander P, Yliperttula M. Microvesicle- and exosome-mediated drug delivery enhances the cytotoxicity of Paclitaxel in autologous prostate cancer cells. J Control Release. 2015;220(Pt B):727-737. doi:10.1016/j.jconrel.2015.09.031

159. Krishnan SR, Luk F, Brown RD, Suen H, Kwan Y, Bebawy M. Isolation of human $\mathrm{CD} 138(+)$ microparticles from the plasma of patients with multiple myeloma. Neoplasia. 2016;18(1):25-32. doi:10.1016/j.neo.2015.11.011

160. Chen G, Zhu JY, Zhang ZL, et al. Transformation of cell-derived microparticles into quantum-dot-labeled nanovectors for antitumor siRNA delivery. Angew Chem Int Ed Engl. 2015;54 (3):1036-1040. doi:10.1002/anie.201410223

161. Barry OP, FitzGerald GA. Mechanisms of cellular activation by platelet microparticles. Thromb Haemost. 1999;82(2):794-800. doi:10.1055/s-0037-1615913

162. Gonda DD, Akers JC, Kim R, et al. Neuro-oncologic applications of exosomes, microvesicles, and other nano-sized extracellular particles. Neurosurgery. 2013;72(4):501-510. doi:10.1227/ NEU.0b013e3182846e63

163. Viaud S, Terme M, Flament C, et al. Dendritic cell-derived exosomes promote natural killer cell activation and proliferation: a role for NKG2D ligands and IL-15Ralpha. PLoS One. 2009;4 (3):e4942. doi:10.1371/journal.pone.0004942

164. Escudier B, Dorval T, Chaput N, et al. Vaccination of metastatic melanoma patients with autologous dendritic cell (DC) derived-exosomes: results of the first phase I clinical trial $J$ Transl Med. 2005;3(1):10. doi:10.1186/1479-5876-3-10

165. Andre F, Schartz NE, Movassagh M, et al. Malignant effusions and immunogenic tumour-derived exosomes. Lancet. 2002;360 (9329):295-305. doi:10.1016/S0140-6736(02)09552-1
166. Dolo V, Ginestra A, Cassarà D, et al. Selective localization of matrix metalloproteinase 9 , beta1 integrins, and human lymphocyte antigen class I molecules on membrane vesicles shed by $8701-\mathrm{BC}$ breast carcinoma cells. Cancer Res. 1998;58(19):4468-4474.

167. Stec M, Baj-Krzyworzeka M, Baran J, et al. Isolation and characterization of circulating micro(nano) vesicles in the plasma of colorectal cancer patients and their interactions with tumor cells. Oncol Rep. 2015;34(5):2768-2775. doi:10.3892/or.2015.4228

168. Janowska-Wieczorek A, Wysoczynski M, Kijowski J, et al. Microvesicles derived from activated platelets induce metastasis and angiogenesis in lung cancer. Int $J$ Cancer. 2005;113 (5):752-760. doi:10.1002/ijc.20657

169. Mezouar S, Mege D, Darbousset R, et al. Involvement of platelet-derived microparticles in tumor progression and thrombosis. Semin Oncol. 2014;41(3):346-358. doi:10.1053/j. seminoncol.2014.04.010

170. Clancy JW, Sedgwick A, Rosse C, et al. Regulated delivery of molecular cargo to invasive tumour-derived microvesicles. Nat Commun. 2015;6(1):6919. doi:10.1038/ncomms7919

171. Jaiswal R, Luk F, Dalla PV, Grau GE, Bebawy M. Breast cancer-derived microparticles display tissue selectivity in the transfer of resistance proteins to cells. PLoS One. 2013;8(4): e61515. doi:10.1371/journal.pone.0061515

172. Shi J, Heegaard CW, Rasmussen JT, Gilbert GE. Lactadherin binds selectively to membranes containing phosphatidyl-L-serine and increased curvature. Biochim Biophys Acta. 2004;1667 (1):82-90. doi:10.1016/j.bbamem.2004.09.006

173. Stec M, Szatanek R, Baj-Krzyworzeka M, et al. Interactions of tumour-derived micro(nano) vesicles with human gastric cancer cells. J Transl Med. 2015;13(1):376. doi:10.1186/s12967-0150737-0

174. Morello M, Minciacchi VR, de Candia P, et al. Large oncosomes mediate intercellular transfer of functional microRNA. Cell Cycle. 2013;12(22):3526-3536. doi:10.4161/cc.26539

175. Guo L, Zhang Y, Wei R, Zhang X, Wang C, Feng M. Proinflammatory macrophage-derived microvesicles exhibit tumor tropism dependent on CCL2/CCR2 signaling axis and promote drug delivery via SNARE-mediated membrane fusion. Theranostics. 2020;10(15):6581-6598. doi:10.7150/ thno. 45528

176. Dolo V, D'Ascenzo S, Violini S, et al. Matrix-degrading proteinases are shed in membrane vesicles by ovarian cancer cells in vivo and in vitro. Clin Exp Metastasis. 1999;17(2):131-140. doi:10.1023/A:1006500406240

177. Millimaggi D, Mari M, D'Ascenzo S, et al. Tumor vesicle-associated CD147 modulates the angiogenic capability of endothelial cells. Neoplasia. 2007;9(4):349-357. doi:10.1593/ neo.07133

178. Munster M, Fremder E, Miller V, et al. Anti-VEGF-A affects the angiogenic properties of tumor-derived microparticles. PLoS One. 2014;9(4):e95983. doi:10.1371/journal.pone.0095983

179. Bianco F, Perrotta C, Novellino L, et al. Acid sphingomyelinase activity triggers microparticle release from glial cells. EMBO J. 2009;28(8):1043-1054. doi:10.1038/emboj.2009.45

180. Szczepanski MJ, Szajnik M, Welsh A, Whiteside TL, Boyiadzis M. Blast-derived microvesicles in sera from patients with acute myeloid leukemia suppress natural killer cell function via membrane-associated transforming growth factor-beta1. Haematologica. 2011;96(9):1302-1309. doi:10.3324/ haematol.2010.039743

181. Yamada N, Tsujimura N, Kumazaki M, et al. Colorectal cancer cell-derived microvesicles containing microRNA-1246 promote angiogenesis by activating Smad 1/5/8 signaling elicited by PML down-regulation in endothelial cells. Biochim Biophys Acta. 2014;1839(11):1256-1272. doi:10.1016/j.bbagrm.2014.09.002 
182. Yamada N, Nakagawa Y, Tsujimura N, et al. Role of intracellular and extracellular microRNA-92a in colorectal cancer. Transl Oncol. 2013;6(4):482-492. doi:10.1593/tlo.13280

183. Hulsmans M, Holvoet P. MicroRNA-containing microvesicles regulating inflammation in association with atherosclerotic disease. Cardiovasc Res. 2013;100(1):7-18. doi:10.1093/cvr/ $\operatorname{cvt} 161$

184. Bolukbasi MF, Mizrak A, Ozdener GB, et al. miR-1289 and "Zipcode"-like sequence enrich mRNAs in microvesicles. Mol Ther Nucleic Acids. 2012;1(2):e10. doi:10.1038/ mtna.2011.2

185. He WA, Calore F, Londhe P, Canella A, Guttridge DC, Croce CM. Microvesicles containing miRNAs promote muscle cell death in cancer cachexia via TLR7. Proc Natl Acad Sci USA. 2014;111(12):4525-4529. doi:10.1073/pnas.1402714111

186. Akao Y, Iio A, Itoh T, et al. Microvesicle-mediated RNA molecule delivery system using monocytes/macrophages. Mol Ther. 2011;19(2):395-399. doi:10.1038/mt.2010.254
187. Liu Y, Zhao L, Li D, et al. Microvesicle-delivery miR-150 promotes tumorigenesis by up-regulating VEGF, and the neutralization of miR-150 attenuate tumor development. Protein Cell. 2013;4(12):932-941. doi:10.1007/s13238-013-3092-z

188. Berchem G, Noman MZ, Bosseler M, et al. Hypoxic tumorderived microvesicles negatively regulate NK cell function by a mechanism involving TGF- $\beta$ and miR23a transfer. Oncoimmunology. 2016;5(4):e1062968. doi:10.1080/ 2162402X.2015.1062968

189. Kanada M, Bachmann MH, Hardy JW, et al. Differential fates of biomolecules delivered to target cells via extracellular vesicles. Proc Natl Acad Sci USA. 2015;112(12):E1433-1442. doi:10.1073/pnas.1418401112

190. Ahmadzada T, Kao S, Reid G, Clarke S, Grau GE, HosseiniBeheshti E. Extracellular vesicles as biomarkers in malignant pleural mesothelioma: a review. Crit Rev Oncol Hematol. 2020;150:102949. doi:10.1016/j.critrevonc.2020.102949

\section{Publish your work in this journal}

The International Journal of Nanomedicine is an international, peerreviewed journal focusing on the application of nanotechnology in diagnostics, therapeutics, and drug delivery systems throughout the biomedical field. This journal is indexed on PubMed Central, MedLine, CAS, SciSearch ${ }^{\mathbb{R}}$, Current Contents ${ }^{\mathbb{R}} /$ Clinical Medicine, $^{2}$
Journal Citation Reports/Science Edition, EMBase, Scopus and the Elsevier Bibliographic databases. The manuscript management system is completely online and includes a very quick and fair peer-review system, which is all easy to use. Visit http://www.dovepress.com/ testimonials.php to read real quotes from published authors. 